\title{
A Review of Molecular and Genetic Diagnostics of Myeloid Malignancies with Emphasis on Diagnostics in Bosnia and Herzegovina
}

\begin{abstract}
Amina Kurtovic-Kozaric ${ }^{1,2,3}$, Erna Islamagic ${ }^{2}$, Adna Asic ${ }^{3}$, Lejla Mehinovic-Cavcic ${ }^{2}$, Larisa Besic ${ }^{3}$, Hana Sahinbegovic $^{4,5,6}$, Hana Komic ${ }^{7}$, Sabira Kurtovic ${ }^{8}$, Lejla Burazerovic ${ }^{8}$

${ }^{1}$ Department of Clinical Pathology, Cytology and Human Genetics, Clinical Center of the University of Sarajevo, Sarajevo, Bosnia and Herzegovina, ${ }^{2}$ Faculty of Science, University of Sarajevo, Sarajevo, Bosnia and Herzegovina, ${ }^{3}$ Department of Genetics and Bioengineering, International Burch University, Sarajevo, Bosnia and Herzegovina, ${ }^{4}$ Department of Hematooncology, University Hospital Ostrava, Ostrava, Czech Republic, ${ }^{5}$ Faculty of Medicine, University of Ostrava, Ostrava, Czech Republic, ${ }^{6}$ Faculty of Science, University of Ostrava, Ostrava, Czech Republic, ${ }^{7}$ TIMM Laboratory, Sahlgrenska Center for Cancer Research, University of Gothenburg, Gothenburg, Sweden, ${ }^{8} \mathrm{Hematology}$ Clinic, Clinical Center of the University of Sarajevo, Sarajevo, Bosnia and Herzegovina
\end{abstract}

Correspondence: amina.kozaric@kcus.ba; Tel.: + 38733298 752; Fax.: + 38733297826

Received: 6 March 2021; Accepted: 2 April 2021

\begin{abstract}
Here we describe the major genetic and genomic aberrations found in myeloid malignancies and how those markers are used in patients' diagnosis, prognosis, and targeted treatment. In Bosnia and Herzegovina, cytogenetic and molecular diagnostics for myeloid malignancies have been established and continually improved since 2005 . We report the current state of available diagnostic tools for myeloid malignancies in Bosnia and Herzegovina. Myeloid malignancies are a heterogeneous group of clonal blood diseases characterized by defects in hematopoietic stem cells and myeloid progenitors that lead to abnormal proliferation, differentiation, localization, and self-renewal. Most common myeloid malignancies include myeloproliferative neoplasms (MPNs), myelodysplastic syndrome (MDS), and acute myeloid leukemia (AML). Molecular diagnostics of myeloid malignancies have significantly expanded in the last decade with new genetic and genomic markers for diagnosis, prognosis, and treatment. Conclusion. In the last decade, several new genomic markers important for patient diagnosis, prognosis, and therapy have been discovered that need to be implemented in routine molecular diagnostics not only in developed nations but also in developing nations such as Bosnia and Herzegovina.
\end{abstract}

Key Words: Myeloid Neoplasms • Molecular Diagnostics • Myeloproliferative Neoplasms • Myelodysplastic Syndrome • Acute Myeloid Leukemia.

\section{Introduction and Classification}

Myeloid malignancies are a heterogeneous group of clonal diseases where hematopoietic stem or progenitor cells (HSPCs) are disrupted concerning their self-renewal, proliferation, and differentiation capacity as a result of genetic and epigenetic changes $(1,2)$. The World Health Organization (WHO) classification of myeloid neoplasms was last updated in 2016 (3). According to this classification, myeloid neoplasms include myeloproliferative neoplasms (MPN), mastocytosis, my- eloid/lymphoid neoplasms with eosinophilia and gene rearrangement, myelodysplastic/myeloproliferative neoplasms (MDS/MPN), myelodysplastic syndromes (MDS), myeloid neoplasms with germline predisposition, acute myeloid leukemia and related neoplasms (AML), blastic plasmacytoid dendritic cell neoplasm, and acute leukemias of ambiguous lineage (3).

In this review, molecular and genetic diagnostics of more common myeloid malignancies such as MPN, MDS, and AML will be covered. 


\section{Myeloproliferative Neoplasms (MPNs)}

MPNs are acquired blood malignancies that arise from clonal hematopoiesis through the overproduction of either one or more types of myeloid cell lines. MPNs are classified based on the presence of $B C R-A B L 1$ gene fusion. Chronic myelogenous leukemia (CML) is therefore classified as a Philadelphia-positive MPN, while polycythemia vera (PV), essential thrombocythemia (ET), and primary myelofibrosis (PMF) are classified as Philadelphia-negative MPNs (4-6).

\section{Philadelphia-Negative MPNs: Polycythemia Vera $(P V)$}

$\mathrm{PV}$ is characterized by erythrocytosis, which is often accompanied by leukocytosis and thrombocytosis. The 2016 revision of WHO classification defines three major and one minor criterion for the PV diagnosis. Major criteria are: (1) In men, hemoglobin level $>16.5 \mathrm{~g} / \mathrm{dL}$ or hematocrit $>49 \%$; in women, hemoglobin level $>16.0 \mathrm{~g} / \mathrm{dL}$ or hematocrit level $>48 \%$, or increased red cell mass; (2) Hypercellular bone marrow with panmyelosis; (3) Detection of $J A K 2^{\mathrm{V} 617 \mathrm{~F}}$ mutation or JAK2 mutation within exon 12 . The minor criterion is subnormal erythropoietin level in the patients' serum. PV diagnosis requires confirmation of all three major criteria, or the first two major criteria + minor criterion (3). Treatment includes phlebotomy, hydroxyurea, and interferon- $\alpha$ (4-6).

\section{Philadelphia-Negative MPNs: Essential Thrombocythemia (ET)}

ET is characterized by megakaryocytic hyperplasia and thrombocytosis, which elevated granulocyte levels and splenomegaly may accompany. According to the last revision of the WHO classification, four major and one minor criterion are determined for ET diagnosis. Major criteria are (1) Thrombocyte count $\geq 450 \times 10^{9} / \mathrm{L}$; (2) Prominent proliferation of the megakaryocyte lineage, with mature, enlarged megakaryocytes; (3) Not meeting criteria for PV, PMF, MDS, $B C R-A B L 1^{+} \mathrm{CML}$, or other myeloid neoplasms; (4) Detection of the $J A K 2, C A L R$, or MPL mutations. Minor criterion implies the absence of the reactive thrombocytosis and presence of a clonal marker. ET diagnosis requires meeting four major criteria, or three major criteria and minor criterion (3). Treatment involves salicylic acid and hydroxyurea (4-6).

\section{Philadelphia-Negative MPNs: Primary Myelofibrosis (PMF)}

The main characteristics of PMF include abnormal megakaryocytopoiesis, aberrant blood count, elevated myeloid cell proliferation, fibroblast proliferation, as well as the release of reticulin and collagen which leads to bone marrow fibrosis, extramedullary hematopoiesis, and splenomegaly (4-6). Three major criteria for PMF diagnosis are: (1) Megakaryocytic proliferation and atypia, granulocytic proliferation, decreased erythropoiesis, and absence of reticulin fibrosis $>1^{\text {st }}$ grade; (2) Not meeting criteria for PV, ET, MDS, BCR$A B L 1^{+} \mathrm{CML}$, or other myeloid neoplasms; (3) Detection of the JAK2, CALR, or MPL mutations, or presence of another clonal marker. Minor criteria are (1) Palpable splenomegaly; (2) High activity of LDH; (3) Leukocytosis; (4) Anemia. PMF diagnosis can be confirmed if all three major criteria and one minor criterion are met (3).

\section{Philadelphia-Positive MPN: Chronic Myelogenous Leukemia (CML)}

CML is a Philadelphia chromosome-positive $\left(\mathrm{Ph}^{+}\right)$myeloproliferative disease. The main cause of CML is a reciprocal translocation between chromosomes 9 and 22 in the bone marrow stem cells, which leads to the formation of the BCR-ABL1 fusion gene. BCR-ABL1 protein conditionally activates several key signal transduction pathways responsible for the proliferation, survival, and dissemination of the malignant myeloid clone (7-13). Bone marrow biopsy at diagnosis is necessary for: a) determination of blast cell percentage, $b$ ) assessment of basophils proportion, $\mathrm{c}$ ) the presence of $B C R-A B L 1$ translocation by cytogenetic analysis 
(karyotyping or FISH) or polymerase chain reaction (PCR) (14). The detection of BCR-ABL1 clone at diagnosis and every three months after the initiation of treatment is required for each CML patient. Disease monitoring consists of measuring $B C R-A B L 1$ transcripts by real-time quantitative PCR. Hasford and EUTOS scores were used to predict patients' survival and response to the TKI therapy; however, the new EUTOS Long Term Survival (ELTS) score is more adequate to predict the probability of leukemia-related deaths since the vast majority of CML patients die from the other causes than leukemia (15). A revolutionary advancement in the CML treatment was achieved with a tyrosine kinase inhibitor, such as imatinib mesylate, a drug that specifically blocks the enzymatic activity of the BCR-ABL1 fusion protein (16).

\section{Myelodysplastic Syndrome (MDS)}

MDS is a clonal disorder of hematopoietic stem cells (HSCs) characterized by aberrations in both morphology and maturation of cell precursors of one or several lineages and cytopenia with a tendency of progression to acute myeloid leukemia $(17,18)$. This is a heterogeneous group of malignancies with aberrant proliferation, differentiation, and maturation of HSCs, all of which are evident as morphological changes in myeloid cells. Clinical manifestation includes bone marrow failure, while pathological manifestation includes dysplastic morphology in one or several blood cell lineages in the bone marrow or the peripheral blood. The majority of patients suffer from cytopenia, anemia and require blood transfusions. Less common symptoms include neutropenia and/or thrombocytopenia (17).

\section{Acute Myeloid Leukemia (AML)}

AML is characterized by the clonal proliferation of abnormal, immature myeloid cells. The term acute refers to a disease that develops faster and leads to fatal outcomes in as little as a few months if left untreated (19). It arises due to genetic changes in the DNA of myeloid precursors. It is characterized by an obstruction in differentiation and a continuous division of immature myeloid cells, more precisely leukemic blasts, which impair normal hematopoiesis (20). AML primarily forms in the bone marrow, but in most cases, blasts are also found within the peripheral blood. More precisely, AML is defined as a disease characterized by over $20 \%$ of blasts in the bone marrow or peripheral blood. This may also spread to other parts of the body, such as lymph nodes, spleen, liver, central nervous system, or testicles (21).

\section{Molecular Markers}

\section{Genetic Markers of AML}

Genetic markers, both molecular and cytogenetic, have their diagnostic, prognostic, and therapeutic role. As a part of a diagnostic workup, each AML patient requires both cytogenetic and molecular testing. Regarding molecular markers, studies have identified an overwhelming number of mutations in AML genomes. On average, one AML genome shows five mutations. Nine gene categories relevant for AML pathogenesis have been identified, namely gene fusions, NPM1 mutations, tumor-suppressor genes, DNA methylation genes, signaling genes, chromatin-modifying genes, myeloid transcription factors, cohesin complex genes, and spliceosomal members (Table 1). The most commonly mutated genes in AML are FLT3 (32\% of all cases), NPM1 (25\%), and DNMT3A (20\%), with the possibility that they are concomitant in the same sample.

FLT3 (Fms-like tyrosine kinase 3) is a gene that encodes a class III receptor tyrosine kinase present in both humans and mice (Figure 1). When a ligand binds to FLT3, it gets dimerized and autophosphorylated, leading to the activation of PI3K/ AKT and RAS/MAPK pathways (22). Increased expression levels have been seen in $70 \%$ to $100 \%$ of AML cases; thus, it was hypothesized that FLT3 expression plays a role in the survival and proliferation of leukemic blasts (23). The most commonly seen mutation in the FLT3 gene in AML is internal tandem duplication (24), while the second most 
Table 1. AML Risk Stratification and Genomic Classification. Risk Stratification Is Based on Molecular and Cytogenetic Abnormalities and Is Used for Therapeutical Strategies*

\begin{tabular}{|c|c|c|}
\hline AML risk stratification & Molecular markers & Cytogenetics \\
\hline \multirow{3}{*}{ Favorable } & NPM1 mutated & $\mathrm{t}(8 ; 21)(\mathrm{q} 22 ; \mathrm{q} 22.1) ; R U N X 1-R U N X 1 T 1$ \\
\hline & FLT3 wild type & $\mathrm{t}(15 ; 17)(\mathrm{q} 24 ; \mathrm{q} 21), P M L-R A R A$ \\
\hline & CEBPA biallelic mutation & $\operatorname{inv}(16)$ or $\mathrm{t}(16 ; 16) ; C B F B-M Y H 11$ \\
\hline \multirow{3}{*}{ Intermediate } & $\begin{array}{l}\text { NPM1 mutated \& } \\
\text { FLT3-ITD mutated }\end{array}$ & $\mathrm{t}(9 ; 11)(\mathrm{p} 21.3 ; \mathrm{q} 23.3) ;$ MLLT3-KMT2A \\
\hline & $\begin{array}{l}\text { NPM1 wild type \& FLT3 } \\
\text { wild type }\end{array}$ & $\mathrm{t}(6 ; 9)(\mathrm{p} 23 ; \mathrm{q} 34.1) ; D E K-N U P 214$ \\
\hline & - & Cytogenetic abnormalities not classified as favorable or adverse \\
\hline \multirow{5}{*}{ Adverse } & $\begin{array}{l}\text { NPM1 wild type \& FLT3- } \\
\text { ITD mutated }\end{array}$ & $\mathrm{t}(\mathrm{v} ; 11 \mathrm{q} 23.3) ; K M T 2 A(\mathrm{MLL})$ rearrangement \\
\hline & RUNX1 mutated & $\mathrm{t}(9 ; 22)(\mathrm{q} 34.1 ; \mathrm{q} 11.2) ; B C R-A B L 1$ \\
\hline & ASXL1 mutated & $\operatorname{inv}(3)(\mathrm{q} 21.3 \mathrm{q} 26.2)$ or $\mathrm{t}(3 ; 3)(\mathrm{q} 21.3 ; \mathrm{q} 26.2) ;$ GATA2,MECOM(EVI1) \\
\hline & TP53 mutated & -5 or del $(5 q) ;-7 ;-17 / \operatorname{del}(17 p)$ \\
\hline & - & Complex karyotype, monosomy \\
\hline \multicolumn{3}{|l|}{ AML Genomic Classification } \\
\hline Classes of AML & Frequency of all AML (\%) & Additional mutated genes \\
\hline NPM1 mutant & 30 & DNMT3A (50\%), FLT3 (40\%), Cohesin (15\%), NRAS (15\%), IDH (15\%), TET2 (15\%) \\
\hline Chromatin-spliceosome & 13 & RUNX1 (40\%), MLL (20\%), ASXL1 (20\%), DNMT3A (20\%), SRSF2 (20\%), FLT3 (15\%), \\
\hline$t(15 ; 17)$ & 13 & FLT3 (35\%), WT1 (15\%) \\
\hline $\begin{array}{l}\text { TP53/chromosomal } \\
\text { aneuploidy }\end{array}$ & 10 & - \\
\hline$t(8 ; 21)$ & 7 & KIT (25\%), NRAS (20\%), Cohesin (20\%), ASXL1 (20\%) \\
\hline $\operatorname{inv}(16)$ & 5 & NRAS (40\%), KIT (35\%), FLT3 (20\%) \\
\hline $\mathrm{t}(\mathrm{v} ; 11 \mathrm{q} 23)$ & 4 & KRAS (20\%), NRAS (20\%) \\
\hline biCEPBA & 4 & GATA2 (30\%), NRAS (30\%) \\
\hline$t(9 ; 22)$ & 1 & - \\
\hline$t(6 ; 9)$ & 1 & FLT3 (70\%) \\
\hline$t(5 ; 11)$ & 1 & FLT3 (80\%) \\
\hline $\operatorname{inv}(3)$ & 1 & - \\
\hline Other translocations & 1 & - \\
\hline IDH2 R172 & 1 & - \\
\hline
\end{tabular}

"AML genomic classification presents classes of AML based on genomic and cytogenetic abnormalities; Cohesin = RAD21; SMC1A, SMC3 wild type = not mutated, normal.

common one is FLT3 activation loop point mutation. Internal tandem duplications (ITD) in FLT3 account for $24 \%$, while the activation loop mutations are seen in $7 \%$ of AML patients. Therefore, $30 \%$ of AML patients have acquired mutations in the FLT3 gene, making it the most mutated gene in AML (25). Mutations in the FLT3 gene result in cellular proliferation, resistance to apoptosis, and DNA defective repair (26). The identification of FLT3 mutations is essential because of the availability of FLT3 inhibitors, which are part of the standard treatment of AML.

CEBPA (CCAAT/enhancer-binding protein $\alpha$ ) encodes transcriptional factor with leucine zipper 

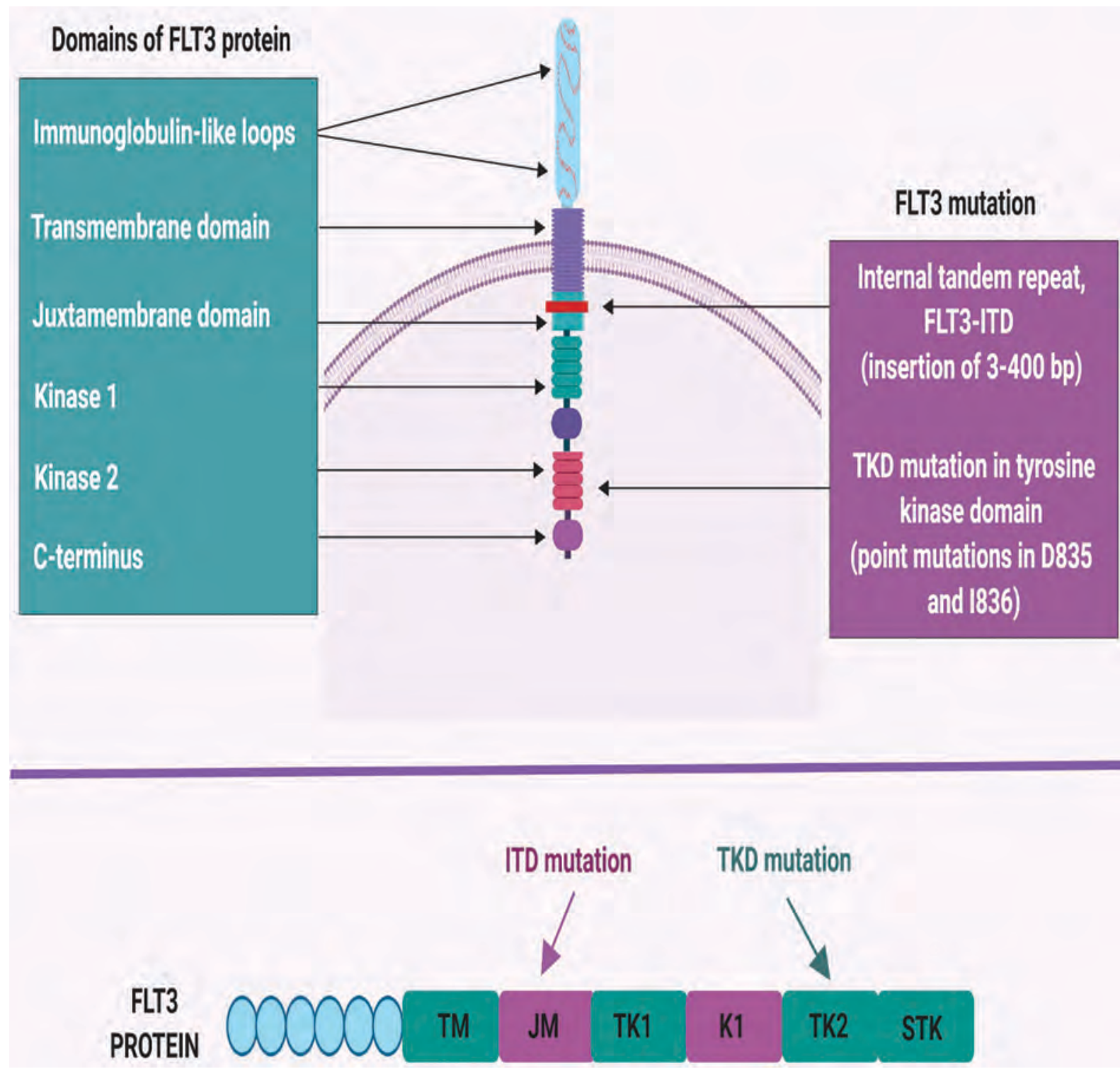

Figure 1. FLT3 mutations are among the most common mutations in AML patients. Two types of mutations have been identified: internal tandem duplication (ITD) mutation and TKD (tyrosine kinase domain) mutations. ITD mutations are more common than TKD mutations. ITD mutations lead to 3-400 bp insertions in the JM domain, while TKD mutations (D835 and 1836) are point mutations in the TK2 domain. Created in Biorender.

domain involved in cell cycle regulation $(27,28)$, proliferation, and differentiation of the myeloid lineage (28). Nonsense and frameshift mutations are frequent in the $\mathrm{N}$-terminal region, while inframe indels are typical for the C-terminal region of the protein (27). In general, 5-15\% of AML patients have single- or double-mutated CEBPA. Double-mutated CEBPA (CEBPAdm) is related to the characteristic gene expression profile that defines a specific subgroup of AML patients with a more favorable prognosis $(3,29)$. Coexisting mutations in genes ASXL1, RUNX1, NPM1, and FLT3-ITD, are more frequently present in CEB$P A$ sm (single-mutated) cases (30).

NPM1 (Nucleophosmin 1) is a gene that encodes multifunctional NPM1 protein, primarily localized in the nucleolus. It functions as a molecular chaperone that transports ribosomal proteins 
through the nuclear membrane (31). Mutations in NPM1 have been linked to tumorigenesis, as NPM1 was found to be frequently overexpressed in diverse solid tumors and involved in different translocations and deletions (32). It was shown that NPM1 is mutated in $25 \%$ of AML patients, making it one of the most frequently mutated genes in this type of cancer (33). Four-base insertions in exon 12 of NPM1 are seen in $75-80 \%$ of cases (34). All mutations in exon 12 are frameshift mutations, causing changes in the C-terminal region, resulting in the loss of two tryptophan residues and creating a new nuclear export sequence (NES) domain. Consequently, mutant NPM1 (called NPM1c) protein is exported to the cytoplasm instead of in the nucleus.

KIT, a proto-oncogene type III tyrosine kinase, is a receptor for stem cell factors expressed on the surface of the leukemic blast (35). Mutations in this gene are seen either in exon 8 or in codon 816 , the latter resulting in a formation of the activation loop. $20-30 \%$ of AML patients with $t(8 ; 21)$ and inv(16)/t(16;16) carry mutations in KIT (36). They cause the activation of MAPK and PI3K/AKT pathway and STAT3/STAT5 signaling that aid in cancer development (37).

RAS protein family is a diverse group of proteins that activate various receptors, which further trigger downstream effector pathways. These control cell proliferation, differentiation, and survival (38). Guanine nucleotide-binding proteins, which include NRAS, KRAS, and HRAS, are involved in hematopoiesis. RAS activation may result from either a mutation in RAS itself or FLT3 or KIT; NRAS and KRAS mutations are seen in about 15\% to $25 \%$ of AML patients. RAS mutations activate $\mathrm{PI} 3 \mathrm{~K} / \mathrm{Akt} / \mathrm{mTOR}$ and the RAF/MEK/ERK proproliferative signaling pathways (38).

DNMT3A (DNA methyltransferase 3A) catalyzes methylation of 5-methylcytosines and is important for differentiation of the embryo and hematopoietic stem cells. There are three active DNA methyltransferases in mammals - DNMT1, DNMT3A, and DNMT3B. They are primarily involved in DNA methylation but also in genetic imprinting, differentiation, X-chromosome in- activation, proliferation, and apoptosis (39). $\mathrm{Mu}-$ tations in DNMT3A occur in more than $30 \%$ of AML patients with normal karyotype (40). Lossof-function mutations in DNMT3A halt the hematopoietic cell differentiation and are among the first events in leukemogenesis. Mutated DNMT3A preleukemic cells represent storage for further progression of the disease if additional mutations occur. The most common mutation seen in $\mathrm{DN}$ $M T 3 A$ is at the R882 arginine residue, disrupting the methyltransferase activity. DNMT3A mutations in combination with FLT3 or NPM1 mutations are linked to adverse prognosis (41).

TET2 (a member of the TET family of dioxygenase proteins) mutations occur in $10-25 \%$ of AML (41). TET2 converts 5-methylcytosine to 5-hydroxymethylcytosine, encouraging DNA demethylation. Mutations in TET2 do not promote AML by themselves but instead disrupt the function of the TET2 enzyme, which leads to the clonal expansion of pre-leukemic stem cells. These cells may override normal hematopoiesis with time and favor the accumulation of mutations leading to AML development (42).

IDH1 and IDH2 are NADP-dependent enzymes involved in the KREBS cycle, as IDH1 (isocitrate dehydrogenase 1) and IDH2 (isocitrate dehydrogenase 2) catalyze the oxidative decarboxylation of isocitrate to alpha-ketoglutarate. IDH1 and IDH 2 mutations occur in $20 \%$ of AML patients and are heterozygous (43). The most common mutations are IDH1 R132, IDH2 R140, and IDH2 R172, which have different prognostic value. IDH mutations lead to the formation of a neomorphic enzyme and abnormal accumulation of an oncometabolite, 2-hydroxyglutarate $(44,45)$. Accumulated 2-hydroxyglutarate initiates potentially oncogenic events: it inhibits jumonji-C domain containing proteins involved in histone demethylation, TET2 protein, prolyl/lysyl hydroxylases, and cytochrome $\mathrm{C}$ in the electron-transport chain (41). IDH inhibitors such as enasidenib and ivosidenib were approved in 2018 to treat relapsed/ refractory AML.

Regarding cytogenetic markers, recurrent cytogenetic aberrations are found in about $50 \%$ of 

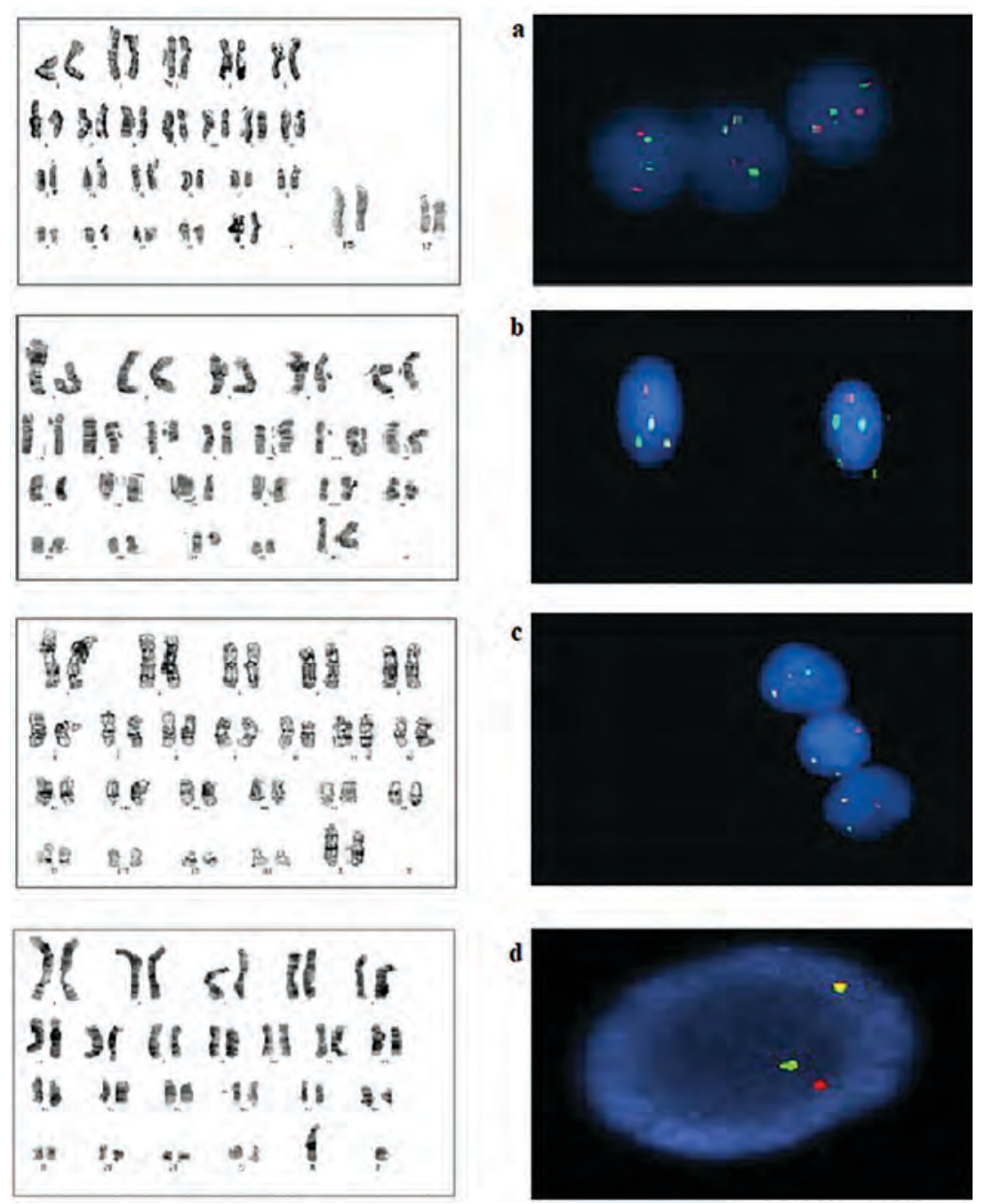

Figure 2. (A) 46,XX,t(15;17)(q22;q21.1) Abnormal female karyotype with translocation between chromosomes 15 and 17. (a) FISH analysis for PML/RARA on two hundred interphase nuclei with 1R1G2F positive signal pattern (1 red signal, 1 green signal, and 2 fusions; Abbott, Abbott Park, Illinois, USA). (B) 46,XX,t(8;21)(q22;q22) Abnormal female karyotype with translocation between chromosomes 8 and 21. (b) Dual color dual fusion translocation FISH probe for RUNX1/RUNX1T1 (Abbott, Abbott Park, Illinois, USA) with abnormal 1R1G2F (1 red signal, 1 green signal, and 2 fusions) pattern. (C) $46, X X, t(9 ; 11)(p 23 ; q 23)$ Abnormal female karyotype with translocation between chromosomes 9 and 11. (c) MLL break a part FISH probe with 1R1G1F (1 red signal, 1 green signal, and 1 fusion) abnormal pattern. (D) 46,XY,inv(16)(p13;q22) Abnormal male karyotype with chromosome 16 inversion. (d) Break apart FISH probe for CBFB with abnormal pattern $1 R 1 G 1 F$ (1 red signal, 1 green signal, and 1 fusion).

all AML patients, where the most common ones are $\mathrm{t}(15 ; 17), \mathrm{t}(8 ; 21), \operatorname{inv}(16), \mathrm{t}(9 ; 11), \operatorname{inv}(3)$, and $\mathrm{t}(6 ; 9)$ (Figure 2). These balanced translocations and inversions are classified as "AML with recurrent genetic abnormalities" in the WHO classification (3). It is worth noting that besides mentioned cytogenetic aberrations, additional abnormalities including complex karyotype (3 or more chromosomal abnormalities), such as -5 or $\operatorname{del}(5 q),-7$ or $\operatorname{del}(7 q), i(17 q)$ or $\mathrm{t}(17 \mathrm{p}),-13$ or $\operatorname{del}(13 \mathrm{q})$, $\operatorname{del}(11 \mathrm{q}), \mathrm{t}(2 ; 11)(\mathrm{p} 21 ; \mathrm{q} 23.3)$, $\mathrm{t}(3 ; 21)(\mathrm{q} 26.2 ; \mathrm{q} 22.1), \quad \mathrm{t}(1 ; 3)$ (p36.3;q21.2), $\quad \mathrm{t}(5 ; 12)(\mathrm{q} 32 ;$ p13.2), t(11;16)(q23.3;p13.3), $\mathrm{t}(5 ; 7)(\mathrm{q} 32 ; \mathrm{q} 11.2), \mathrm{t}(5 ; 17)(\mathrm{q} 32$; $\mathrm{p} 13.2), \mathrm{t}(5 ; 10)(\mathrm{q} 32 ; \mathrm{q} 21.2)$, and $\mathrm{t}(3 ; 5)(\mathrm{q} 25.3 ; \mathrm{q} 35.1)$. These are sufficient to establish the diagnosis of "AML with myelodysplasia-related changes" if the bone marrow has $\geq 20 \%$ blasts (27). Around 50\% of AML patients have normal karyotype without recurrent genetic abnormalities.

The most commonly found abnormalities can be found on the Atlas of Genetics Oncology website. Here we describe two examples: PML-RARA and MLL translocations. PML-RARA translocation, $\mathrm{t}(15 ; 17)(\mathrm{q} 22 ; \mathrm{q} 12)$, involves $P M L$ (promyelocytic leukemia protein) and $R A R A$ (retinoic acid receptor alpha) genes, whereby PML N-terminus is fused with the $\mathrm{C}$ terminal RARA receptor region (Figure 3). PML-RARA fusion protein acts as an irregular retinoic acid receptor with modified DNA-binding and transcription-regulation properties. Different protein isoforms are possible, each resulting in a different clinical description of the disease. At the molecular level, this translocation causes inhibition of myeloid differentiation due to inactive RARA protein and blockage in for- 

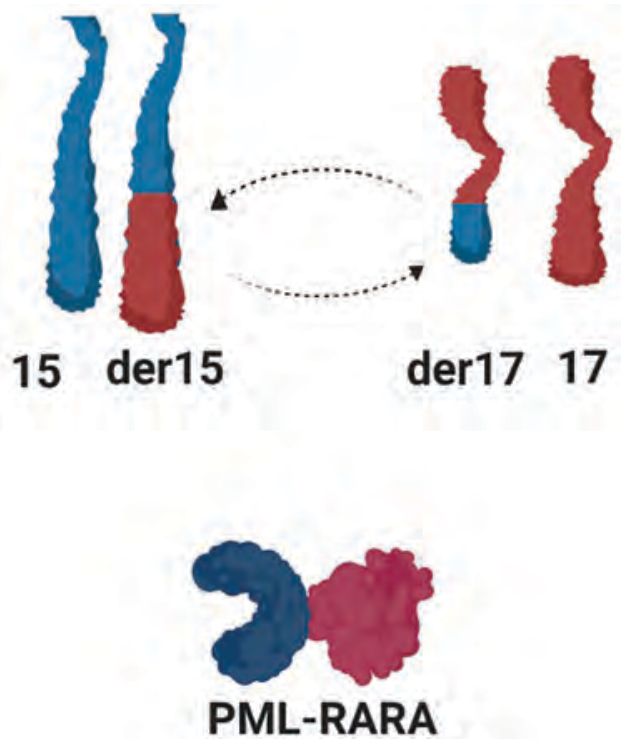

Figure 3. $P M L-R A R a$ results from the translocation between chromosomes 15 and 17 in PML and RARA genes, respectively, leading to the PML-RARa fusion protein.

mation of nuclear bodies, necessary for the proper functioning of the p53-related pathway. Molecular and cytogenetic diagnostics are essential for the fast determination of the presence of $P M L-R A R A$ translocation in a blood or bone marrow sample because of the need for urgent clinical action. Fast FISH assay or RT-PCR are used to detect this translocation within 2-4 hours.

$M L L$, coding for a methyltransferase, can harbor gene rearrangement that has been among the first to be associated with unfavorable patient prognosis (46). Translocations and partial tandem duplications in $M L L$ are seen in $8-10 \%$ of AML. MLL translocates with over 50 different genes, causing the expression of chimeric proteins (47). However, MLL rearrangements show a very low number of potentially cooperating mutations thus indicating that MLL-rearranged leukemias are mostly driven through epigenetic dysregulation (48). Duplication regions are found between exon 5 and 11 and between exon 5 and 12 and are strongly associated with trisomy 11 but have also been noted for karyotypically normal AML (49). $M L L$ rearrangements in AML usually result in the overexpression of BCL2 protein, leading to drug resistance (46).
NCCN and ELN risk stratification of AML is based on the presence of molecular and cytogenetic mutations (Table 1) $(27,50)$. Each AML is categorized as favorable, intermediate, and adverse. The stratification is crucial for treatment strategy and is an integral part of patient evaluation. Even if a genetic mutation may not be included as a prognostic marker, its presence may provide a target for new therapies as with IDH1, IDH2, and KMT2A.

\section{Genetic Markers of CML}

CML's main cause is the reciprocal translocation between chromosomes 9 and 22 in bone marrow stem cells, leading to clonal proliferation of mature granulocytes and their precursors. Translocation $\mathrm{t}(9 ; 22)(\mathrm{q} 34 ; \mathrm{q} 11)$ with characteristic Philadelphia chromosome (shortened as 22q-) is found in $95 \%$ of all CML cases (Figure 4). Depending on exact breakage and rejoining sites, several different BCR-ABL1 proteins might result from this translocation. Protein size can be 210 (p210) or 190 (p190) $\mathrm{kDa}$, depending on the number of amino acids in the BCR primary sequence. p190 is mostly found in acute lymphocytic leukemia (ALL) cases, while p210 is found in both ALL and CML.

The presence of SETBP1 and ETNK1 mutations and the absence of $\mathrm{t}(9 ; 22)$ translocation and mutations in genes associated with MPN characterize atypical CML (aCML), also called BCR-ABL1CML. Mutations in CSF3R are infrequent, present in less than $10 \%$ of aCML cases. Patients with advanced CML exhibit numerous genetic abnormalities, including duplicated Philadelphia chromosome, isochromosome 17(p) resulting in TP53 disturbance, and rarely deletion of p15 and p16 tumor-suppressor genes and RUNX1-EV11 fusion. In addition, gene expression is likely to be deregulated in advanced diseases. This includes both increase in expression (nuclear genes, mitochondrial genes, RNA-binding genes, genes involved in protein synthesis), as well as a decrease (structural integrity and adhesion genes, inflammation, immune response modulators). Finally, several proto-oncogenes and tumor-suppressor genes can be differentially expressed, including $N-R A S, H-R A S$, FLT3, WT1, BCL-2, and PTPN11. 


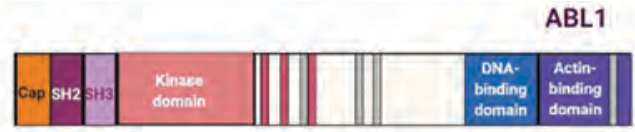

BCR-ABL1
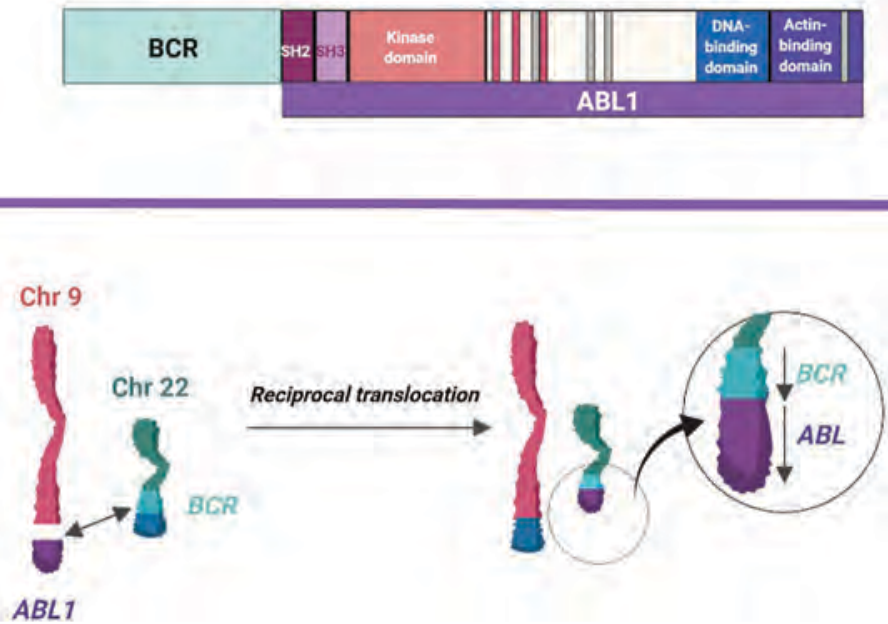

Figure 4. $B C R-A B L 1$ gene fusion results from a reciprocal translocation between long arms of chromosomes 9 and 22, leading to the BCR-ABL1 fusion protein (depicted at the top). Created in Biorender.

\section{Genetic Markers of MPNs}

Over 95\% of patients suffering from Philadelphianegative MPNs harbor either JAK2, CALR, or $M P L$ driver gene mutations. The fourth phenotype driver gene is CSF3R, and mutation in any of these genes is mutually exclusive with the other three. A common characteristic of MPNs is increased JAKSTAT signaling. Besides, TET2, DNMT3A, ASXL1, IDH1/2, EZH2, SF3B1, SRSF2, TP53, NRAS, and $K R A S$ mutations were also reported, mainly in socalled triple-negative patients. These mutations can also appear before or after phenotypic driver mutations, in which case they modify or amplify the effect of those drivers $(5,51)$. Other DNA sequence variants or mutations found in a fraction of MPN patients are TP53, CUX1, IKZF1, NF-E2 (transcriptional regulation), ASXL1, IDH1, IDH2, TET2, EZH2, DNMT3A (epigenetic regulation), SRSF2, $U 2 A F 1$, and $S F 3 B 1$ (RNA splicing). It has been reported that TP53, IDH2, and SRSF2 mutations are over-represented in blast-phase MPN (52). Similarly, ASXL1, EZH2, and SRSF2 mutations in PMF patients are associated with leukemic transformation and poor prognosis.

The three most commonly mutated genes in MPN (JAK2, MPL and CALR) are a part of the MPN diagnostic algorithm. JAK2 (Janus kinase 2) V617F mutation in exon 14 is most abundantly found in the Philadelphia-negative MPNs, namely PV (in around $95 \%$ of cases), ET (around $55 \%$ of cases), and PMF (around $65 \%$ of the cases). This mutation leads to the growth-factor independence in affected cells due to constitutive tyrosine phosphorylation and consequential JAK2 protein activation (5, 6, 51-56). MPL (MPL protooncogene) gene encodes thrombopoietin receptor, and its mutations are found in around $4 \%$ of ET and $10 \%$ of PMF patients, but not in PV patients. Mutations are mostly found in residue W515 in exon 10, including W515L, which results in constitutive activation of downstream signaling pathway even in the absence of thrombopoietin. Other MPL mutations in MPNs are W515S, W515A, S505N, A506T, and A519T. Calreticulin (CALR) is a multifunctional chaperone protein involved in various cellular processes, including cell adhesion (57-60). Recent studies have found CALR mutations in exon 9 in MPN patients who lack the JAK2 or MPL mutations. CALR mutations were reported in ET and PMF patients at a frequency between $20 \%$ and $30 \%$ and accounted for approximately $70 \%$ of JAK2/ MPL-nonmutated ET and around $85 \%$ of JAK2/ $M P L$-nonmutated PMF. They were not reported in PV patients (57-60). Over 36 different frameshift insertions or deletions were reported, all of which results in a novel C-terminal amino acid sequence in the mutated calreticulin, which leads to malfunctioning in calcium-binding and cell growth. The most prominent two mutations are the type 1 and type 2 mutations, which account for over $80 \%$ of the $C A L R$ exon 9 mutations. The type 1 mutation (L367fs*46) is a 52-base pair deletion, while type 2 mutation $\left(\mathrm{K}^{3} 35 \mathrm{fs}^{\star} 47\right)$ is a 5 -base pair TTGTC 
insertion, both of which lead to a frameshift. Both mutations induce a change in the subcellular localization signal by leading to a loss of negatively charged amino acids in the protein C-domain (57-60).

\section{Genetic Markers of MDS}

MDS is associated with two types of mutations: chromosomal aberrations and somatic gene mutations. Common chromosomal aberrations that are associated with MDS are $-5 / 5 q_{-},-7 / 7 q_{-}^{-},+8,20 q^{-}$, $+21,12 \mathrm{p}-, 13 \mathrm{q}-$ and 17p- (Figure 5, Table 2). Their prognostic values are shown in Table 3 . They are detected in $40-60 \%$ of primary MDS patients and more than $80 \%$ of therapy-associated MDSs (61) (Table 1). These aberrations are best detected with karyotyping or microarrays. The affected chromosomal regions often involve tumor-suppressor genes. While these changes are encountered at diagnosis, additional or evolved clones can be found during the clinical progression of the disease and are associated with a poor prognosis.
Table 2. Cytogenetic Abnormalities Found in MDS and Therapy-Related MDS*

\begin{tabular}{|c|c|c|c|}
\hline MDS cytogenetics & Abnormality & MDS (\%) & t-MDS (\%) \\
\hline \multirow[t]{9}{*}{ Unbalanced } & $+8^{*}$ & 10 & - \\
\hline & -7 or $\quad \operatorname{del}(7 q)$ & 10 & 50 \\
\hline & -5 or $\quad$ del $(5 q)$ & 10 & 40 \\
\hline & $\operatorname{del}(20 \mathrm{q})^{*}$ & $5-8$ & - \\
\hline & $-Y^{*}$ & 5 & - \\
\hline & $i(17 q)$ or $t(17 p)$ & $3-5$ & - \\
\hline & -13 or $\operatorname{del}(13 q)$ & 3 & - \\
\hline & $\operatorname{del}(11 q)$ & 3 & - \\
\hline & del(12p) or $t(12 p)$ & 3 & - \\
\hline \multirow[t]{6}{*}{ Balanced } & $\mathrm{t}(11 ; 16)(\mathrm{q} 23 ; \mathrm{p} 13.3)$ & - & 3 \\
\hline & $\mathrm{t}(3 ; 21)(q 26.2 ; q 22.1)$ & - & 2 \\
\hline & $t(1 ; 3)(p 36.3 ; q 21.2)$ & 1 & - \\
\hline & $\mathrm{t}(2 ; 11)(\mathrm{p} 21 ; \mathrm{q} 23)$ & 1 & - \\
\hline & $\operatorname{inv}(3)(q 21 q 26.2)$ & 1 & - \\
\hline & $\mathrm{t}(6 ; 9)(q 23 ; q 34)$ & 1 & - \\
\hline
\end{tabular}

"Table adapted from reference (61); MDS=Myelodysplastic syndrome; $\mathrm{t}$ MDS=Therapy related MDS.

Table 3. Genomic/Molecular Abnormalities in MDS and AML*

\begin{tabular}{llll}
\hline Gene & Frequency in MDS (\%) & Prognosis & Comment \\
\hline RNA splicing & & & \\
\hline SF3B1 & $20-30$ & Favorable & $\begin{array}{l}\text { MDS-rS and MDS-MLD, associated with ring sideroblasts, fewer mutations } \\
\text { in other genes }\end{array}$ \\
\hline SRSF2 & 15 & Unfavorable & CMML phenotype \\
\hline U2AF1 & 10 & Unfavorable & Often with del(20q) \\
\hline ZRSR2 & 5 & Unknown & On X-chromosome, more common in males \\
\hline Epigenetic regulators & $20-30$ & Unknown & Normal karyotype, more frequent in CMML \\
\hline TET2 & $10-15$ & Unfavorable & - \\
\hline DNMT3A & 5 & Unknown & - \\
\hline IDH1 and IDH2 & $5-20$ & Unfavorable & - \\
\hline ASXL1 & 5 & Unfavorable & More common in CMML \\
\hline EZH2 & 5 & Unfavorable & Associated with complex karyotype and high risk disease, few mutations in \\
\hline Transcription and signaling pathways & other genes \\
\hline TP53 & 8 & Unfavorable & Thrombocytopenia, excess blasts \\
\hline RUNX1 & $5-10$ & Unfavorable & Thrombocytopenia, excess blasts, more common in CMML \\
\hline NRAS/KRAS & $5-10$ & Unknown & 50\% of RARS-T, often subclonal \\
\hline JAK2 & 5 & &
\end{tabular}

"Table adapted from reference (68). 

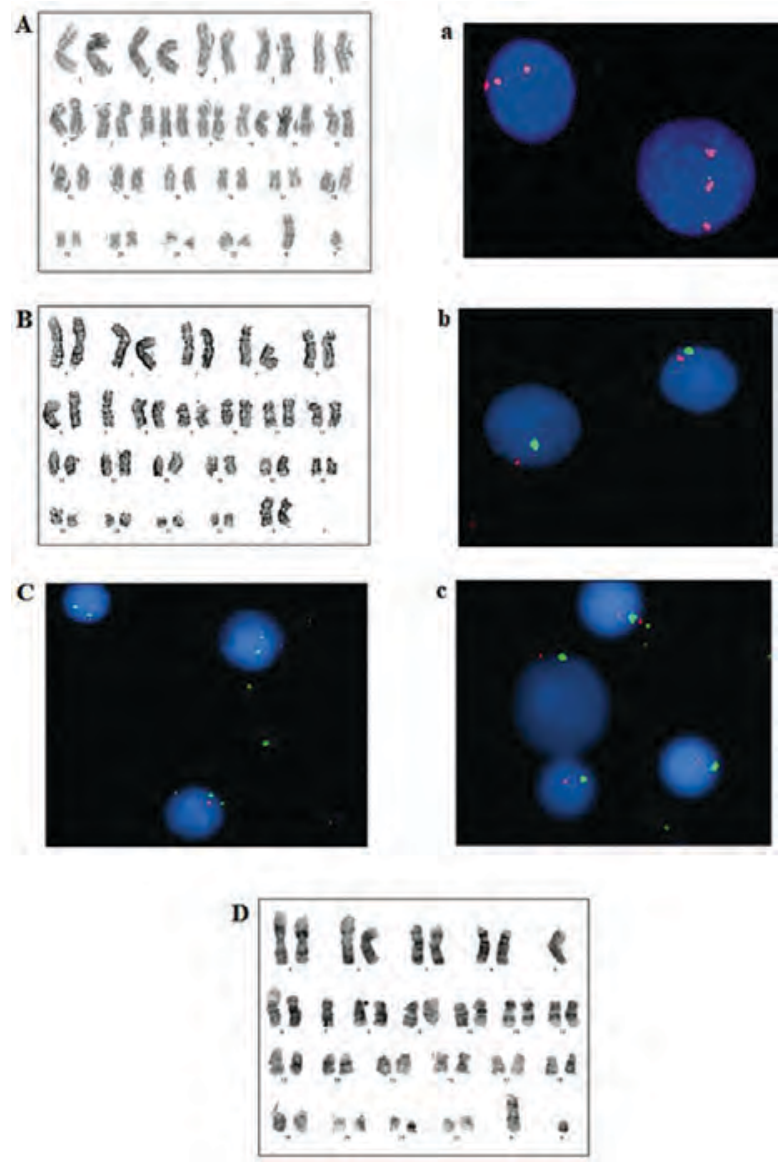

Figure 5. (A) 47, $\mathrm{XY},+8$ Abnormal male karyotype with chromosome 8 trisomy. (a) FISH for centromere of chromosome 8 (Abbott, Abbott Park, Illinois, USA). Trisomy 8 is shown ( 3 red signals). (B) 45,XX,-7 Abnormal female karyotype with a chromosome 7 monosomy. (b) FISH dual color probes for chromosome 7 centromere and D7S522 locus at 7q31 (Abbott, Abbott Park, Illinois, USA). Monosomy 7 is shown with an abnormal signal pattern 1R1G (1 red and 1 green signal). (C-c) FISH analysis for chromosomes 5 and 7 was performed on a patient sample. (C) Dual color probes for loci at $5 \mathrm{p} 15.2$ and $5 q 31$. Deletion is shown with a positive 1R2G scheme (1 red and 2 green signals). (c) Dual color probe for chromosome 7 centromere and D7S522 locus at 7q31. Monosomy of chromosome 7 is shown. (D) 44,XY,-5,-7 Abnormal male karyotype with monosomies of chromosomes 5 and 7 was determined in the analyzed cells.

Regarding somatic mutations, almost half of MDS patients have two or more genes simultaneously mutated (Figure 6). The most efficient meth- od for the simultaneous detection of mutations in several genes is a next-generation sequencing (NGS). Affected genes are involved in RNA splicing, transcription, signaling pathways, and epigenetic regulation. Their prognostic values are presented in Table 2. Mutations in SF3B1 (splicing factor $3 \mathrm{~b}$ subunit 1) are found in one-third of MDS patients). Other spliceosome-associated genes mutated in MDS include SRSF2, U2AF1, and PRPF8. Among the most significant epigenetic factors that mutate in MDS patients are TET2 and DNMT3A. TET2 mutations are found in up to $30 \%$ of all MDS patients and up to $60 \%$ of CMML patients. The most common DNMT3A mutation is R882, and patients with this mutation have an increased chance of AML progression. ASXL1 encodes a polycomb protein involved in histone methylation. Mutations in this gene are found in $15-20 \%$ of MDS patients, usually frameshift or nonsense mutations in exon 12.

Mutations associated with the progression of MDS to secondary AML include SRSF2, SF3B1, U2AF1, ZRSR2, ASXL1, EZH2, BCOR, and STAG2. These mutations occur in MDS and continue through sAML. Mutations in $I D H 1$ and $I D H 2$ are found at frequencies around 5\%, with a high occurrence in high-risk MDS (around 23\%). Most mutations are missense, including R132 in IDH1 and R172K in IDH2 (Table 2) (43, 62-68). The detection of the mutations mentioned above leads to clonal expansion. However, it is worth noting that those mutations can also be detected, particularly TET2, ASXL1, DNMT3A, and TP53, in healthy aging populations, a phenomenon called clonal hematopoiesis of indeterminate potential (CHIP) (53-55). CHIP is defined as the presence of at least $2 \%$ of a somatic mutation in peripheral blood and the absence of malignant hematological disease. Currently, somatic mutations are not a part of the clinical diagnosis of MDS. CHIP likely transitions to MDS through a complex interaction of several factors within HSC and bone marrow microenvironment. 


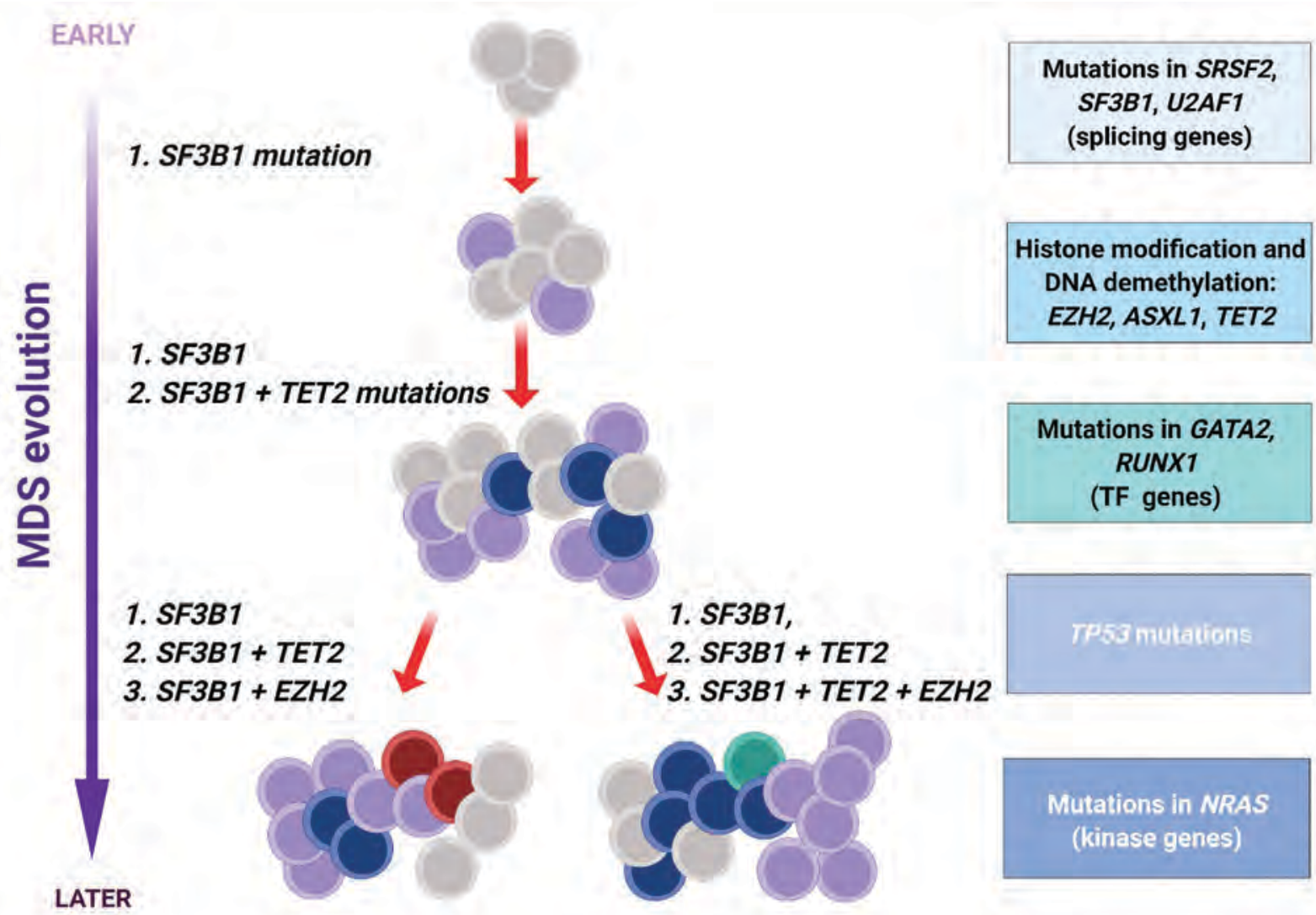

Figure 6. Clonal evolution of MDS. Initial clones develop mutations in splicing factors such as SF3B1, SRSF2, or U2AF1. Later events typically involve TP53 and NRAS mutations, leading to several different clones in MDS patients. Created in Biorender.

\section{Molecular and Genetic Techniques}

\section{Cytogenetics}

Cytogenetic analysis of peripheral blood and bone marrow aspirates is the golden diagnostic standard for myeloid malignancies. AML, MDS, MPN, $\mathrm{CML}$, and other myeloid malignancies rely on cytogenetic analysis for both diagnosis and prognosis. Conventional cytogenetic analysis is mandatory in the diagnostic evaluation of AML. Standard cytogenetic analysis refers to karyotyping, where 20 metaphases are screened for chromosomal abnormalities such as translocations, deletions, duplications, inversions, trisomies, monosomies, and other abnormalities. The karyotype is considered complex if it consists of three or more abnormalities. Reporting abnormalities is standardized through ISCN (International System for $\mathrm{Hu}$ - man Cytogenetic Nomenclature), which contains guidelines on cytogenetic formulations. Clonality, or the presence of one or more clones with unique abnormalities, can easily be deduced from cytogenetic formulas (56). If cytogenetic analysis cannot be obtained, fluorescence in situ hybridization is used to detect specific translocations or deletions, such as $\mathrm{t}(8 ; 21), \operatorname{inv}(16), \mathrm{t}(15 ; 17)$, del $5 \mathrm{q}$, del7q, and del17p.

Cytogenetic abnormalities have diagnostic and prognostic values. The presence of $t(9 ; 22)$ in a myeloid patient is diagnostic of chronic myeloid leukemia when taken in the context of clinical parameters (one should also be aware of the AML with $\mathrm{t}(9 ; 22))$. Similarly, other translocations such as $t(15 ; 17), t(11 ; ?)$, and $t(6 ; 9)$ are essential to detect in AML patients because of therapy management and prognosis. All these abnormalities are part of the WHO classification of tumors of hematopoi- 


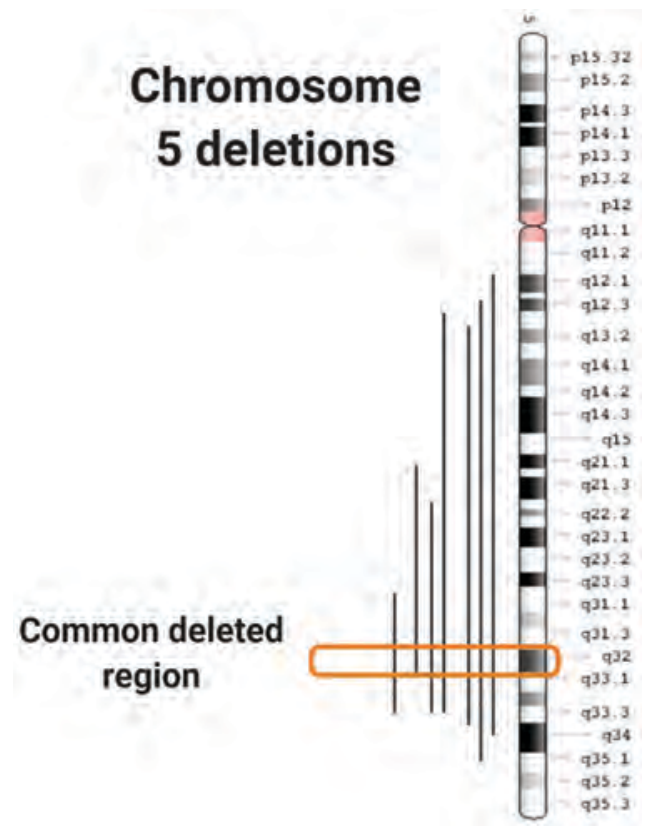

Figure 7. Deletions of the long arm of chromosome 5 are defined as del5q syndrome, a subtype of MDS with a more indolent disease course. Deletions can be larger or smaller, where the common deleted region is in 5 q32. Created in Biorender.

etic and lymphoid tissues. Furthermore, deletion of the long arm of chromosome 5 , or del $5 \mathrm{q}$, is a unique subset of MDS, referred to as del5q syndrome (Figure 7). Classical prognostic markers for MDS are deletion del7q, monosomy of 7 , or trisomy 8 , which carry a worse prognosis. Complex karyotypes are generally considered unfavorable prognostic markers (56).

The urgent karyotype is typically requested for AML or other hematological malignancies such as ALL or Burkitt lymphoma and can be signed out within 3-7 days. Once the bone marrow aspirate or peripheral blood are received, mononuclear cells are counted and the appropriate number placed in liquid media for 24-72 h. Once the cells have divided and proliferated, they are harvested, cytoplasm removed, fixed, dropped onto slides, and stained with trypsin and Giemsa (GTG banding). The analysis is conducted on 20 metaphases using a light microscope.

After $B C R-A B L 1$ is confirmed by qualitative or quantitative PCR in CML patients, karyotyping is the next step to demonstrate additional chromo- somal abnormalities besides the Ph chromosome; if the $\mathrm{Ph}$ chromosome is not found, FISH analysis is necessary to detect variant translocations (6970). Karyotyping is also an optimal method for analyzing additional chromosomal abnormalities (ACA), previously divided as major and minor route ACA (69). The current classification includes low-risk and high-risk ACA (additional Ph, additional 19 chromosome, trisomy 8, isochromosome $17 q$, deletion $-7 / 7 q$ ) (69). The presence of high-risk ACA is related to a worse prognosis in the CML patients, who are accordingly classified as high-risk patients, and they usually show resistance to the TKI therapy (70-73).

\section{Polymerase Chain Reaction - PCR}

Endpoint polymerase chain reaction (PCR) used to amplify DNA segments of interest is applied in all branches of molecular studies, including molecular diagnostics of myeloid malignancies. The method has shown better sensitivity than the direct sequencing of PCR-amplified DNA (detecting mutations with variant allele fractions between 1 and $3 \%)$. The major drawback of this method is that many of the protocols are designed in a manner that only the mutant sequence will be amplified if present (such as the protocol designed for the JAK2V617F mutation), which may potentially lead to false-negative results, but also prevents differentiation between heterozygous and wild-type mutated samples (74-79). Jeong et al. (2016) developed an AS-PCR-based system for CALR type $1\left(\mathrm{~L} 367 \mathrm{fs}^{\star} 46\right)$ and type $2\left(\mathrm{~K} 385 \mathrm{fs}^{\star} 47\right)$ mutation screening (80).

Amplification refractory mutations system (ARMS)-PCR is often used to detect single base variations or minor deletions. This screening method allows for the amplification of mutant and wild-type alleles in a single reaction with the addition of a second pair of primers. The primary deployment of ARMS-PCR is the detection of single nucleotide polymorphisms (SNPs), which makes it ideal for JAK2 variant screening. Today, the method has been optimized to detect the mutation with as little as a $0.05 \%$ variant allele fraction. A 
drawback of the method is the lack of quantification of wild type-mutant allele ratios $(74,81,82)$. The JAK2V617F ARMS-PCR primers designed by Jones et al. (2005) involves two outer control primers (FO and $\mathrm{RO}$ ) which are complementary to the region flanking exon 14 of the JAK2 gene, while the inner primers are complementary to the region flanking the $\mathrm{G}$ (in case of a wild-type sequence) or the $\mathrm{T}$ (in case of a mutation) (83).

Allele-specific oligonucleotide-polymerase chain reaction (ASO-PCR), also recommended to detect specific frequent mutations in the BCR-ABL1 kinase domain, is a more sensitive method compared to Sanger sequencing (84). The mechanism for TKI resistance and a main cause of suboptimal response in CML patients is the presence of mutations in the $B C R-A B L 1$ kinase domain $(85,86)$. However, the detection of mutations is more efficient and sensitive using next-generation sequencing (NGS) (87-90).

\section{Real-Time Quantitative PCR}

Real-time PCR enables simultaneous amplification, quantification, and analysis of the variants of interest via fluorescent molecules' detection by fluorescent excitation based on the change in fluorescence during amplification. The combination of real-time PCR and DNA-melting curve analysis is a time- and cost-effective system. Its high sensitivity and specificity make it the best alternative to direct sequencing. Besides, due to its quantification property, this method allows for detecting wild type-mutant allele ratios (76).

Type of BCR-ABL1 transcript (e13a3/b2a2, $\mathrm{e} 14 \mathrm{a} 3 / \mathrm{b} 3 \mathrm{a} 2$, or atypical) in the peripheral blood should be identified by qualitative RT-PCR (nested PCR) at diagnosis and optionally during the followup of the patient to assess the response to therapy (91). A quantitative PCR (qPCR) is used to evaluate $B C R-A B L 1$ transcript level. It is not required at the diagnosis; however, it is mandatory to perform qPCR every three months during follow-up to track patients' molecular response to TKI (11).

The molecular response is defined as the ratio of $B C R-A B L 1$ transcripts and ABL transcripts/GUSB transcripts, according to the International Scale (IS), and it should be reported as a percentage on the $\log$ scale. Values $1 \%(2 \log ), 0.1 \%(3 \log ), 0.01 \%$ (4 log), $0.0032 \%(4.5 \log$ ), and $0.001 \%(5 \log )$ are below the baseline defined in the IRIS study (9295). Complete cytogenetic response (CCyR) is defined as $\leq 1 \% B C R-A B L 1$ transcript level. Major molecular response $\left(\mathrm{MMR}, \mathrm{MR}^{3}\right)$ is equivalent to $\leq 0.1 \% B C R-A B L 1$ transcript level; deep molecular response is determined by $\mathrm{MR}^{4}(\leq 0.01 \%)$ and $\mathrm{MR}^{5}$ $(\leq 0.001 \%)(92,93)$. It is recommended to use the term "molecularly undetectable leukemia" with the reported number of ABL1/GUSB transcripts instead of "complete molecular response" (94). Monitoring of $B C R-A B L 1$ transcript level (time point at 3, 6, and 12 months of follow-up) is important in determining patient's response to TKI therapy (optimal, warning, or failure). Achievement of MMR is crucial to assess eligibility for TKI continuation. At 12 months, optimal response is defined as $\leq 0.1 \% B C R-A B L 1$ transcript (TKI treatment should be continued), warning as $\leq 0.1$ $1 \% B C R-A B L 1$ transcript level (considering the treatment change), and failure as $\leq 1 \% B C R-A B L 1$ transcript (TKI should be changed) (92-97).

\section{Sanger Sequencing}

Sanger sequencing is a molecular method for determining nucleotide sequence in a DNA molecule based on in vitro DNA replication, most widely performed to detect the single-nucleotide variants (SNVs) and small indels (98). Sanger (conventional) sequencing has been the golden standard for the detection of SNVs because of the high-level of accuracy (99.99\%), longer read length (1000 $\mathrm{bp}$ ), and cost-effectiveness for a smaller number of samples compared to the next-generation sequencing (NGS) (99). Thus, Sanger sequencing helps discriminate true genetic alterations from errors caused by NGS (99-101). However, below a threshold of $20 \%$, the mosaic allele's detection is not possible.

In $\mathrm{Ph}^{-} \mathrm{MPN}$ patients negative for JAK2 and CALR mutations, Sanger sequencing can be used for detection and discrimination of 
W515L (type 1, 1544G>T) and W515K (type 2, 1543_1544TG>AA) mutations in MPL gene (exon 10) (102). This method is performed for the sequencing of the $B C R-A B L 1$ gene and detection of the most common $B C R-A B L 1$ kinase domain mutations related to the TKI resistance (like T315I, E255K, E255V, Y253H, Y253F) in $\mathrm{Ph}^{+} \mathrm{CML}$ and ALL patients, and it is less sensitive compared to the ASO-PCR (103). In the MDS and AML subclones, the vast majority of alterations in the DNA sequence are precisely detected at the lower allele fractions, which cannot be reported using Sanger sequencing due to its limitations regarding sensitivity $(100,101)$.

\section{Next-Generation Sequencing (NGS)}

Next-generation sequencing (NGS) allows identifying mutations with variant allele fractions of a minimum of $1 \%$ or lower variant allele fractions, leading to discoveries of rare mutations. The detection of rare mutations provides a better understanding of the disease complexity and prognostic relevance. Discoveries of rare variants have also led to the classification of novel subsets of hematologic diseases, enabling new targeted therapies. Furthermore, NGS is used to quantify variant allele fraction, which is of great importance as it was reported that mutational burden is connected to prognosis in clonal hematopoiesis (104-107).

NGS is a fast, massively parallel/deep sequencing technology, with higher error rates $(\sim 0.1-15 \%)$ and generally shorter read lengths than Sanger sequencing. Two main NGS applications are shortread and long-read sequencing. While short-read sequencing is cheaper, more accurate, and generally used for clinical variant discovery, the longread approach is more suitable for full-length sequencing isoforms and de novo genome assembly applications.

There are two main types of short-read NGS technologies: sequencing by ligation (SBL) and sequencing by synthesis (SBS). SBL approaches use a fluorophore-bound probe sequence that hybridizes to a DNA fragment and ligates to an adjacent oligonucleotide for imaging purposes. The base(s) identity complementary to positions within the probes are identified by the emission spectrum of the fluorophore. SBS approach is polymerasedependent, and nucleotide incorporation into an elongating strand is detected by special signals (fluorophores or a change in ionic concentration). In most short-read sequencing cases, DNA is clonally amplified on a solid surface, and the signal is distinguished from the background noise by placing identical copies of DNA fragments into a welldefined area. To ensure massive parallelization of the process, millions of individual SBL or SBS reaction centers are formed, each with its clonal DNA template. A sequencing platform collects information from these reaction centers simultaneously, providing parallel sequencing of many millions of DNA molecules. SBS can be further classified into cyclic reversible termination (CRT) and single-nucleotide addition (SNA). CRT method is characterized by the use of terminator molecules, similar to Sanger sequencing. In contrast, the SNA method uses a single signal to detect the dNTP addition to an elongating strand. Long repetitive elements, copy number alterations, and structural variations important for disease onset, development, or prognosis are not captured by short-read paired-end technologies. Long-read technology can provide continuous sequences from 10 kilobases to several megabases directly from native DNA. Long reads help transcriptomic research, as they can capture the entire mRNA transcripts, allowing the identification of precise exon junctions and gene isoforms. There are two main types of long-read technologies: single-molecule real-time sequencing (SMRT) and synthetic approach. The SMRT method does not require chemical cycling for added dNTPs. It does not rely on a clonal population of amplified DNA fragments to generate a detectable signal, in contrast to short-read approaches (108). Synthetic long-read technology relies on existing reads sequenced by short-read technology to construct longer reads in silico using barcodes' power.

Some of the NGS applications are de novo sequencing (sequencing and construction of new genome or transcriptome), resequencing, target- 
ed resequencing, metagenomics and meta-transcriptomics, DNA- and RNA-protein interactions (ChIP-seq), methylation sequencing, and transcriptome or RNA sequencing (mRNA, miRNA, snRNA). Among many different NGS myeloid panels available, two Illumina sequencing panels (TruSight and AmpliSeq) target the most relevant genes in AML, MPN, MDS, CMML, CML, and JMML (juvenile myelomonocytic leukemia). TruSight Myeloid sequencing panel provides an assessment of 15 full and 39 partial genes (tumor suppressor genes and oncogenic spots). AmpliSeq Myeloid sequencing panel enables analysis of both DNA and RNA in a single assay, with 40 key DNA target genes and 29 RNA fusion driver genes. It allows the detection of SNVs, indels, and gene fusions.

The challenges of NGS in the diagnostics of myeloid malignancies are reviewed by Bacher et al. (90). They reviewed bioinformatics tools to discriminate leukemia-initiating mutations from incidental passenger germline mutations vs. somatic mutations and somatic vs. CHIP mutations. A recent study by Duncavage et al. (2021) tested and streamlined the whole-genome sequencing (WGS) approach (ChromoSeq) for diagnosis and prognosis of AML and MDS patients (109). ChromoSeq provides comprehensive genomic profiling of clinically relevant AML/MDS mutations. Genomic profiling of 263 patients (including 235 that had previously undergone cytogenetic analysis) by WGS detected all 91 copy-number alterations and 40 recurrent translocations previously identified by cytogenetics. Furthermore, it provided new genetic information for 40 out of 235 patients (17\%) that had not been detected by conventional cytogenetic analysis. New copy-number alterations were identified in 14 patients with conclusive and in 13 patients either inconclusive or ambiguous cytogenetic results. Additionally, new structural variants were found in 13 patients. By using prospective sequencing of samples from 117 consecutive patients, WGS provided new genetic information for 29 patients (24.8\%), and 19 of them (16.2\%) were reclassified into risk groups. WGS also allowed stratification of Patients with inconclusive cytoge- netic analysis results into risk groups. In conclusion, ChromoSeq provided a greater diagnostic yield and more efficient risk stratification based on standard risk categories, and could potentially be a good replacement for conventional cytogenetic analysis (109).

\section{Molecular Diagnostics of Myeloid Malignancies in Bosnia and Herzegovina}

Hematological malignancies have increased significantly in the last 20 years in Bosnia and Herzegovina compared to European data $(110,111)$. The possible causes of the increase in the number of patients have not yet been clarified. Cytogenetic tools, i.e., karyotyping, have been established in 2005 at the University Clinical Center Tuzla (UKCT), in 2007 at the Clinical Center of the University of Sarajevo (KCUS), and later in University Clinical Center of Republic of Srpska in Banja Luka (UKCBL).

The largest cytogenetic laboratory is in KCUS, Sarajevo, which receives patient samples from all cantons of the Federation of Bosnia and Herzegovina except Tuzla. FISH (hematological and tissue) is only performed in KCUS, with a wide variety of panels for myeloid malignancies, including MDS panel (del5, del/mono 7, trisomy 8), AML (t(15;17), $t(8 ; 21)$, inv(16), MLL, etc.). A molecular test for CML, quantitative $B C R-A B L 1$, is performed in Sarajevo and Tuzla, where Sarajevo conducts about 70 samples every three months for current CML patients. Other CML tests include karyotype, FISH, qualitative nested PCR, and the detection of the most common $B C R-A B L 1$ kinase domain mutations using ASO-PCR. For MPN, JAK2 is detected by real-time PCR using qualitative and quantitative assays. CALR mutations type 1 and type 2 are detected by ASO-PCR. MPL mutations are detected by Sanger sequencing. For AML, Invivoscribe can detect FLT3 mutations on the capillary sequencer and NPM1 mutations on real-time PCR. The Myeloid panel on NGS is currently in development.

In order to understand the state of diagnostics of myeloid malignancies, we conducted a retro- 
spective study on myeloid neoplasms from the Sarajevo Canton in the period from 1995 to 2015 . We found 268 patients, including AML $\mathrm{N}=64), \mathrm{Ph}(-)$ MPN N=102), Ph(+)MPN (CML) N=47), MDS $\mathrm{N}=51$ ), MDS/MPN N=4) (unpublished data, 111). The unique issue with CML patients in Bosnia and Herzegovina was that many of them had to wait for the start of treatment with tyrosine kinase inhibitors. We have analyzed the effects of delayed treatment in detail previously, are be summarized below. In Bosnia and Herzegovina, TKI therapy has been available since 2005. First frontline TKI therapy was imatinib (Glivec, first-generation TKI); however, due to lack of insurance cover, patients received therapy on a first-come-first-served basis (112). In resource-poor countries like Bosnia and Herzegovina, TKI therapy's availability and monitoring of the disease are limited (113-115). Until 2013, when generic formulations of imatinib were introduced, a certain number of CML patients had to wait for the TKI therapy for an extended period. These patients had worse responses to the therapy, progression or transformation of the disease, and lower survival rate (112). It was shown that generic versions of imatinib in Bosnia and Herzegovina (Anzovip, Meaxin, Plivatinib) are cost-effective, and response to the therapy was similar to the response to Glivec (115-117). In 2011, nilotinib (Tasigna, Novartis, second-generation TKI) became available as front- or second-line therapy, and it was designed to overcome specific $B C R-A B L 1 \mathrm{mu}-$ tations in imatinib-resistant patients $(85,87,118$ 121). Our previous studies showed that nilotinib might be a more potent TKI therapy than imatinib for treating CML patients with a delayed start of therapy (both Glivec and generic alternatives) $(112,116)$. In addition, several international studies showed the superiority of 2GTKI over 1GTKI in terms of efficacy $(72,120-122)$. Besides standard TKI therapies, novel therapies for CML have emerged, specifically for T315I-mutated CML. Asciminib is a Specifically Targeting the ABL Myristoyl Pocket (STAMP) inhibitor capable of blocking BCR-ABL1 activity via allosteric binding to the myristoyl residue distinct to the BCR-ABL1 kinase domain (KD) (123). Asciminib blocks both, wild- type and mutated BCR-ABL1 fusion protein, and has potential to overcome resistence to the frontline 1GTKI or 2GTKI (124).

\section{Conclusions}

Myeloid malignancies are a heterogeneous group of blood disorders in which myeloid cells show aberrant proliferation, differentiation, and localization. In the last decade, several new discoveries regarding the genetic makeup of these diseases have led to the expansion of molecular genetic and genomic testing needed for diagnosis, prognosis, and therapy. Molecular diagnostics is required for determining the most suitable treatment, such as FLT3 or IDH inhibitors in AML. It is presumed that myeloid gene panels will soon be incorporated in disease guidelines and will become a routine molecular test needed for patient diagnosis and prognosis.

Conflict of Interest: The authors declare that they have no conflict of interest.

\section{References}

1. Murati A, Brecqueville M, Devillier R, Mozziconacci MJ, Gelsi-Boyer V, Birnbaum D. Myeloid malignancies: mutations, models and management. BMC Cancer. 2012;12:304.

2. Zeidner JF, Roy D, Perl A, Gojo I. Myeloid Malignancies. The American Cancer Society's Oncology in Practice: Clinical Management. 1st ed. New Jersey, US: WileyBlackwell; 2018. p. 397-421.

3. Arber DA, Orazi A, Hasserjian R, Thiele J, Borowitz MJ, Le Beau MM, et al. The 2016 revision to the World Health Organization classification of myeloid neoplasms and acute leukemia. Blood. 2016;127(20):2391-405.

4. Boissinot M, Vilaine M, Hermouet S. The Hepatocyte Growth Factor (HGF)/Met Axis: A Neglected Target in the Treatment of Chronic Myeloproliferative Neoplasms?. Cancers (Basel). 2014;6(3):1631-69.

5. Choi CW, Bang SM, Jang S, Jung CW, Kim HJ, Kim HY, et al. Guidelines for the management of myeloproliferative neoplasms. Korean J Intern Med. 2015;30(6):771-88.

6. Furtado LV, Betz BL. Diagnostic Molecular Pathology. Cambridge, MA: Academic Press; 2016.

7. Thompson PA, Kantarjian HM, Cortes JE. Diagnosis and Treatment of Chronic Myeloid Leukemia in 2015. Mayo Clin Proc. 2015;90(10):1440-54. 
8. Jabbour E, Kantarjian H. Chronic myeloid leukemia: 2018 update on diagnosis, therapy and monitoring. Am J Hematol. 2018;93(3):442-59.

9. Eden RE, Coviello JM. Chronic Myelogenous Leukemia. In: StatPearls. Treasure Island (FL): StatPearls Publishing; 2020.

10. Pasternak G, Hochhaus A, Schultheis B, Hehlmann R. Chronic myelogenous leukemia: molecular and cellular aspects. J Cancer Res Clin Oncol. 1998;124(12):643-60.

11. Baccarani M, Cortes J, Pane F, Niederwieser D, Saglio G, Apperley J, et al. Chronic myeloid leukemia: an update of concepts and management recommendations of European LeukemiaNet. J Clin Oncol. 2009;27(35):6041-51.

12. Baccarani M, Deininger MW, Rosti G, Hochhaus A, Soverini S, Apperley JF, et al. European LeukemiaNet recommendations for the management of chronic myeloid leukemia: 2013. Blood. 2013;122(6):872-84.

13. Baccarani M, Saglio G, Goldman J, Hochhaus A, Simonsson B, Appelbaum F, et al. Evolving concepts in the management of chronic myeloid leukemia: recommendations from an expert panel on behalf of the European LeukemiaNet. Blood. 2006;108(6):1809-20.

14. Khoury HJ, Williams LA, Atallah E, Hehlmann R. Chronic myeloid leukemia: what every practitioner needs to know in 2017. Am Soc Clin Oncol Educ Book. 2017;37:468-79.

15. Pfirrmann M, Baccarani M, Saussele S, Guilhot J, Cervantes F, Ossenkoppele G, et al. Prognosis of long-term survival considering disease-specific death in patients with chronic myeloid leukemia. Leukemia. 2016;30(1):4856.

16. An X, Tiwari AK, Sun Y, Ding PR, Ashby CR Jr, Chen ZS. BCR-ABL tyrosine kinase inhibitors in the treatment of Philadelphia chromosome positive chronic myeloid leukemia: a review. Leuk Res. 2010;34(10):1255-68.

17. Greenberg PL, Young NS, Gattermann N. Myelodysplastic syndromes. Hematology Am Soc Hematol Educ Program. 2002;136-61.

18. Sperling AS, Gibson CJ, Ebert BL. The genetics of myelodysplastic syndrome: from clonal haematopoiesis to secondary leukaemia. Nat Rev Cancer. 2017;17(1):5-19.

19. Robak T, Wierzbowska A. Current and emerging therapies for acute myeloid leukemia. Clin Ther. 2009;31(2):2349-70.

20. Agarwal A, Bolosky WJ, Wilson DB, Eide CA, Olson SB, Fan G, et al. Differentiation of leukemic blasts is not completely blocked in acute myeloid leukemia. Proc Natl Acad Sci U S A. 2019;116(49):24593-9.

21. Dunphy CH, O’Malley DP, Perkins SL, Chang CC. Analysis of immunohistochemical markers in bone marrow sections to evaluate for myelodysplastic syndromes and acute myeloid leukemias. Appl Immunohistochem Mol Morphol. 2007;15(2):154-9.

22. Leung AYH, Man C, Kwong Y. FLT3 inhibition : a moving and evolving target in acute myeloid leukaemia. Leukemia. 2012;27(2):260-8.
23. Birg BF, Courcoul M, Rosnet O, Bardin F, Pebusque M, Marchetto S, et al. Expression of the FMS/KIT-like gene FLT3 in human acute leukemias of the myeloid and lymphoid lineages. Blood. 1992;80(10):2584-93.

24. Kiyoi H, Naoe T, Yokota S, Nakao M, Minami S, Kuriyama $\mathrm{K}$, et al. Internal tandem duplication of FLT3 associated with leukocytosis in acute promyelocytic leukemia. Leukemia. 1997;11(9):1447-52.

25. Gilliland G, Griffin J. The roles of FLT3 in hematopoiesis and leukemia. Blood. 2002;100(5):1532-42.

26. Small D. Targeting FLT3 for the Treatment of Leukemia. Semin Hematol. 2008;45(2):S17-21.

27. Dohner H, Estey E, Grimwade D, Amadori S, Appelbaum FR, Buchner T, et al. Diagnosis and management of AML in adults: 2017 ELN recommendations from an international expert panel. Blood. 2017;129(4):424-47.

28. Zhang Y, Wang F, Chen X, Zhang Y, Wang M, Liu H, et al. Companion gene mutations and their clinical significance in AML with double mutant CEBPA. Cancer Gene Ther. 2020;27(7-8):599-606.

29. Wouters BJ, Löwenberg B, Erpelinck-Verschueren CA, van Putten WL, Valk PJ, Delwel R. Double CEBPA mutations, but not single CEBPA mutations, define a subgroup of acute myeloid leukemia with a distinctive gene expression profile that is uniquely associated with a favorable outcome. Blood. 2009;113(13):3088-91.

30. Fasan A, Haferlach C, Alpermann T, Jeromin S, Grossmann $\mathrm{V}$, Eder $\mathrm{C}$, et al. The role of different genetic subtypes of CEBPA mutated AML. Leukemia. 2014;28(4):794-803.

31. Borer RA, Nigg EA, Francisco S. Major Nucleolar Proteins Shuttle between Nucleus and Cytoplasm. Cell. 1989;56(3):379-90.

32. Grisendi S, Mecucci C, Falini B, Pandolfi PP. Nucleophosmin and cancer. Nature. 2006;6(7):493-505.

33. Falini B, Mecucci C, Tiacci E, Alcalay M, Rosati R, Pasqualucci L, et al. Cytoplasmic Nucleophosmin in Acute Myelogenous Leukemia with a Normal Karyotype. N Engl J Med. 2005;352(3):254-66.

34. Falini B, Martelli MP, Sportoletti P, Liso A, Tiacci E. Acute myeloid leukemia with mutated nucleophosmin (NPM1): is it a distinct entity? Blood. 2011;117(4):1109-21.

35. Meyer SC, Levine RL. Translational implications of somatic genomics in acute myeloid leukaemia. Lancet Oncol. 2014;15(9):e382-94.

36. Paschka P, Marcucci G, Ruppert AS, Mro K, Chen H, Kittles RA, et al. Adverse Prognostic Significance of KIT Mutations in Adult Acute Myeloid Leukemia With inv(16) and $\mathrm{t}(8 ; 21)$ : A Cancer and Leukemia Group B Study. J Clin Oncol. 2015;24(24):3904-11.

37. Kindler T, Breitenbuecher F, Marx A, Beck J, Hess G, Weinkauf B, et al. Efficacy and safety of imatinib in adult patients with c-kit - positive acute myeloid leukemia. Blood. 2004;103(10):3644-55. 
38. Schubbert S, Shannon K, Bollag G. Hyperactive Ras in developmental disorders and cancer. Nat Rev Cancer. 2007;7(4):295-308.

39. Jurkowska RZ, Jurkowski TP, Jeltsch A. Structure and Function of Mammalian DNA Methyltransferases. ChemBioChem. 2011;12(2):206-22.

40. Nebbioso A, Benedetti R, Conte M, Iside C, Altucci L. Genetic mutations in epigenetic modifiers as therapeutic targets in acute myeloid leukemia. Expert Opin Ther Targets. 2015;19(9):1187-202.

41. Falini B, Sportoletti P, Brunetti L, Martelli MP. Perspectives for therapeutic targeting of gene mutations in acute myeloid leukaemia with normal cytogenetics. Br J Haematol. 2015;170(3):305-22.

42. Nakajima H, Kunimoto H. TET2 as an epigenetic master regulator for normal and malignant hematopoiesis. Cancer Sci. 2014;105(9):1093-9.

43. Marcucci G, Maharry K, Wu Y, Radmacher MD, Mro K, Holland KB, et al. IDH1 and IDH2 Gene Mutations Identify Novel Molecular Subsets Within De Novo Cytogenetically Normal Acute Myeloid Leukemia : A Cancer and Leukemia Group B Study. J Clin Oncol. 2010;28(14):234855.

44. Ward PS, Patel J, Wise DR, Abdel-Wahab O, Bennett BD, Coller HA, et al. The Common Feature of Leukemia-Associated IDH1 and IDH2 Mutations Is a Neomorphic Enzyme Activity Converting a -Ketoglutarate to 2-Hydroxyglutarate. Cancer Cell. 2010;17(3):225-34.

45. Gross S, Cairns RA, Minden MD, Driggers EM, Bittinger MA, Jang HG, et al. Cancer-associated metabolite 2-hydroxyglutarate accumulates in acute myelogenous leukemia with isocitrate dehydrogenase 1 and 2 mutations. J Exp Med. 2010;207(2):3-8.

46. Sakamoto KM, Grant S, Saleiro D, Crispino JD, Hijiya $\mathrm{N}$, Giles $\mathrm{F}$, et al. Targeting novel signaling pathways for resistant acute myeloid leukemia. Mol Genet Metab. 2015;114(3):397-402.

47. Muntean AG, Hess JL. The pathogenesis of mixed-lineage leukemia. Annu Rev Pathol. 2012;7:283-301.

48. Dobbins S, Sherborne A, Ma Y, Bardini M, Biondi A, Cazzaniga $G$, et al. The Silent Mutational Landscape of Infant MLL-AF4 pro-B Acute Lymphoblastic Leukemia. Genes, Chromosom Cancer. 2013;52(10):954-60.

49. Schnittger S, Kinkelin U, Schoch C, Heinecke A, Haase D, Haferlach T, et al. Screening for MLL tandem duplication in 387 unselected patients with AML identify a prognostically unfavorable subset of AML. Leukemia. 2000;14(5):796-804.

50. Tallman MS, Wang ES, Altman JK, Appelbaum FR, Bhatt VR, Bixby D, et al. Acute Myeloid Leukemia, Version 3.2019, NCCN Clinical Practice Guidelines in Oncology. J Natl Compr Canc Netw. 2019;17(6):721-49.

51. Mead AJ, Mullally A. Myeloproliferative neoplasm stem cells. Blood. 2017;129(12):1607-16.
52. Tefferi A, Thiele J, Vardiman JW. The 2008 World Health Organization classification system for myeloproliferative neoplasms: order out of chaos. Cancer. 2009;115(17):3842-7.

53. Bowman RL, Busque L, Levine RL. Clonal Hematopoiesis and Evolution to Hematopoietic Malignancies. Cell Stem Cell. 2018;22(2):157-70.

54. Gibson CJ, Steensma DP. New Insights from Studies of Clonal Hematopoiesis. Clin Cancer Res. 2018;24(19):4633-42.

55. Jaiswal S, Natarajan P, Silver AJ, Gibson CJ, Bick AG, Shvartz E, et al. Clonal Hematopoiesis and Risk of Atherosclerotic Cardiovascular Disease. N Engl J Med. 2017;377(2):111-21.

56. McGowan-Jordan J, Simons A, Schmid M. An International System for Human Cytogenomic Nomenclature (2016). Basel, Switzerland: Karger Publishers; 2016.

57. Klampfl T, Gisslinger H, Harutyunyan AS, Nivarthi $H$, Rumi E, Milosevic JD, et al. Somatic mutations of calreticulin in myeloproliferative neoplasms. N Engl J Med. 2013;369(25):2379-90.

58. Michalak M, Corbett EF, Mesaeli N, Nakamura K, Opas M. Calreticulin: one protein, one gene, many functions. Biochem J. 1999;344(2):281-92.

59. Nangalia J, Massie CE, Baxter EJ, Nice FL, Gundem G, Wedge DC, et al. Somatic CALR mutations in myeloproliferative neoplasms with nonmutated JAK2. N Engl J Med. 2013;369(25):2391-405.

60. Tefferi A, Wassie EA, Guglielmelli P, Gangat N, Belachew AA, Lasho TL, et al. Type 1 versus Type 2 calreticulin mutations in essential thrombocythemia: a collaborative study of 1027 patients. Am J Hematol. 2014;89(8):E121-4.

61. Visconte V, Tiu RV, Rogers HJ. Pathogenesis of myelodysplastic syndromes: an overview of molecular and non-molecular aspects of the disease. Blood Res. 2014;49(4);216-27.

62. DiNardo CD, Propert KJ, Loren AW, Paietta E, Sun Z, Levine RL, et al. Serum 2-hydroxyglutarate levels predict isocitrate dehydrogenase mutations and clinical outcome in acute myeloid leukemia. Blood. 2013;121(24):4917-24.

63. Figueroa ME, Abdel-Wahab O, Lu C, Ward PS, Patel J, Shih A, et al. Leukemic IDH1 and IDH2 mutations result in a hypermethylation phenotype, disrupt TET2 function, and impair hematopoietic differentiation. Cancer Cell. 2010;18(6):553-67.

64. Kosmider O, Gelsi-Boyer V, Slama L, Dreyfus F, BeyneRauzy O, Quesnel B, et al. Mutations of IDH1 and IDH2 genes in early and accelerated phases of myelodysplastic syndromes and MDS/myeloproliferative neoplasms. Leukemia. 2010;24(5):1094-6.

65. Medeiros BC, Fathi AT, DiNardo CD, Pollyea DA, Chan $\mathrm{SM}$, Swords R. Isocitrate dehydrogenase mutations in myeloid malignancies. Leukemia. 2017;31(2):272-81.

66. Mondesir J, Willekens C, Touat M, de Botton S. IDH1 and IDH2 mutations as novel therapeutic targets: current perspectives. J Blood Med. 2016;7:171-80. 
67. Patel JP, Gönen M, Figueroa ME, Fernandez H, Sun Z, Racevskis J, et al. Prognostic relevance of integrated genetic profiling in acute myeloid leukemia. N Engl J Med. 2012;366(12):1079-89.

68. Bejar R. Clinical and genetic predictors of prognosis in myelodysplastic syndromes. Haematologica. 2014;99(6);956-64.

69. Wang W, Cortes JE, Tang G, Khoury JD, Wang S, Bueso-Ramos CE, et al. Risk stratification of chromosomal abnormalities in chronic myelogenous leukemia in the era of tyrosine kinase inhibitor therapy. Blood. 2016;127(22):2742-50.

70. Zhang Z, Chen Z, Jiang M, Liu S, Guo Y, Wan L, et al. Heterogeneous BCR-ABL1 signal patterns identified by fluorescence in situ hybridization are associated with leukemic clonal evolution and poorer prognosis in BCRABL1 positive leukemia. BMC Cancer. 2019;19(1):935.

71. Hehlmann R, Voskanyan A, Lauseker M, Pfirrmann M, Kalmanti L, Rinaldetti S, et al. High-risk additional chromosomal abnormalities in CML herald death by blast crisis already at low blast levels. Blood. 2019;134(Suppl 1):666.

72. Hochhaus A, Saglio G, Hughes TP, Larson RA, Kim DW, Issaragrisil $\mathrm{S}$, et al. Long-term benefits and risks of frontline nilotinib vs imatinib for chronic myeloid leukemia in chronic phase: 5-year update of the randomized ENESTnd trial. Leukemia. 2016;30(5):1044-54.

73. Hochhaus A, Larson RA, Guilhot F, Radich JP, Branford $S$, Hughes TP, et al. Long-term outcomes of imatinib treatment for chronic myeloid leukemia. N Engl J Med. 2017;376(10):917-27.

74. Chen Q, Lu P, Jones AV, Cross NC, Silver RT, Wang YL. Amplification refractory mutation system, a highly sensitive and simple polymerase chain reaction assay, for the detection of JAK2 V617F mutation in chronic myeloproliferative disorders. J Mol Diagn. 2007;9(2):272-6.

75. Darawi MN, Ai-Vyrn C, Ramasamy K, Hua PPJ, Pin TM, Kamaruzzaman SB, et al. Allele-specific polymerase chain reaction for the detection of Alzheimer's disease-related single nucleotide polymorphisms. BMC Med Genet. 2013;14:27.

76. Gaudet M, Fara AG, Beritognolo I, Sabatti M. Single Nucleotide Polymorphisms. New York, NY: Humana Press; 2009.

77. Heim M, Meyer UA. Genotyping of poor metabolisers of debrisoquine by allele-specific PCR amplification. Lancet. 1990;336(8714):529-32.

78. Steensma DP. JAK2 V617F in myeloid disorders: molecular diagnostic techniques and their clinical utility: a paper from the 2005 William Beaumont Hospital Symposium on Molecular Pathology. J Mol Diagn. 2006;8(4):397-526.

79. Ugozzoli L, Wallace RB. Allele-specific polymerase chain reaction. Methods. 1991;2(1):42-8.
80. Jeong JH, Lee HT, Seo JY, Seo YH, Kim KH, Kim MJ, et al. Screening PCR Versus Sanger Sequencing: Detection of CALR Mutations in Patients With Thrombocytosis. Ann Lab Med. 2016;36(4):291-9.

81. McLornan D, Percy M, McMullin MF. JAK2 V617F: a single mutation in the myeloproliferative group of disorders. Ulster Med J. 2006;75(2):112-9.

82. Vannucchi AM, Pancrazzi A, Bogani C, Antonioli E, Guglielmelli P. A quantitative assay for JAK2(V617F) mutation in myeloproliferative disorders by ARMS-PCR and capillary electrophoresis. Leukemia. 2006;20(6):1055-60.

83. Jones AV, Kreil S, Zoi K, Waghorn K, Curtis C, Zhang $\mathrm{L}$, et al. Widespread occurrence of the JAK2 V617F mutation in chronic myeloproliferative disorders. Blood. 2005;106(6):2162-8.

84. Kang HY, Hwang JY, Kim SH, Goh HG, Kim M, Kim DW. Comparison of allele specific oligonucleotide-polymerase chain reaction and direct sequencing for high throughput screening of ABL kinase domain mutations in chronic myeloid leukemia resistant to imatinib. Haematologica. 2006;91(5):659-62.

85. Branford S, Rudzki Z, Walsh S, Parkinson I, Grigg A, Szer J, et al. Detection of BCR-ABL mutations in patients with CML treated with imatinib is virtually always accompanied by clinical resistance, and mutations in the ATP phosphate-binding loop (P-loop) are associated with a poor prognosis. Blood. 2003;102(1):276-83.

86. Parker WT, Yeoman AL, Jamison BA, Yeung DT, Scott HS, Hughes TP, et al. BCR-ABL1 kinase domain mutations may persist at very low levels for many years and lead to subsequent TKI resistance. Br J Cancer. 2013;109(6):1593-8.

87. Soverini S, Abruzzese E, Bocchia M, Bonifacio M, Galimberti S, Gozzini A, et al. Next-generation sequencing for BCR-ABL1 kinase domain mutation testing in patients with chronic myeloid leukemia: a position paper. J Hematol Oncol. 2019;12(1):131.

88. Berenstein R, Blau IW, Kar A, Cay R, Sindram A, Seide $\mathrm{C}$, et al. Comparative examination of various PCR-based methods for DNMT3A and IDH1/2 mutations identification in acute myeloid leukemia. J Exp Clin Cancer Res. 2014;33(1):44.

89. Levine RL, Valk PJM. Next-generation sequencing in the diagnosis and minimal residual disease assessment of acute myeloid leukemia. Haematologica. 2019;104(5):86871.

90. Bacher U, Shumilov E, Flach J, Porret N, Joncourt R, Wiedemann $\mathrm{G}$, et al. Challenges in the introduction of nextgeneration sequencing (NGS) for diagnostics of myeloid malignancies into clinical routine use. Blood Cancer J. 2018;8(11):113.

91. Baccarani M, Castagnetti F, Gugliotta G, Rosti G, Soverini $\mathrm{S}$, Albeer A, et al. The proportion of different BCR-ABL1 transcript types in chronic myeloid leukemia. An international overview. Leukemia. 2019;33(5):1173-83. 
92. Branford S, Fletcher L, Cross NC, Müller MC, Hochhaus A, Kim DW, et al. Desirable performance characteristics for BCRABL measurement on an international reporting scale to allow consistent interpretation of individual patient response and comparison of response rates between clinical trials. Blood. 2008;112(8):3330-8.

93. Cross NC, White HE, Müller MC, Saglio G, Hochhaus A. Standardized definitions of molecular response in chronic myeloid leukemia. Leukemia. 2012;26(10):2172-5.

94. Cross NC, White HE, Colomer D, Ehrencrona H, Foroni L, Gottardi E, et al. Laboratory recommendations for scoring deep molecular responses following treatment for chronic myeloid leukemia. Leukemia. 2015;29(5):999-1003.

95. Guilhot J, Preudhomme C, Mahon FX, Guilhot F. Analyzing molecular response in chronic myeloid leukemia clinical trials: pitfalls and golden rules. Cancer. 2015;121(4):490-7.

96. Hochhaus A, Baccarani M, Silver RT, Schiffer C, Apperley JF, Cervantes F, et al. European LeukemiaNet 2020 recommendations for treating chronic myeloid leukemia. Leukemia. 2020;34(4):966-84.

97. Lauseker M, Hanfstein B, Haferlach C, Schnittger S, Pfirrmann M, Fabarius A, et al. Equivalence of BCR-ABL transcript levels with complete cytogenetic remission in patients with chronic myeloid leukemia in chronic phase. J Cancer Res Clin Oncol. 2014;140(11):1965-9.

98. Heather JM, Chain B. The sequence of sequencers: The history of sequencing DNA. Genomics. 2016;107(1):1-8.

99. Chan EY. Next-generation sequencing methods: impact of sequencing accuracy on SNP discovery. Methods Mol Biol. 2009;578:95-111.

100. Albitar F, Wanlong M, Diep K, De Dios I, Agersborg S, Thangavelu M, et al. Deep Sequencing of Cell-Free Peripheral Blood DNA as a Reliable Method for Confirming the Diagnosis of Myelodysplastic Syndrome. Genet Test Mol Biomarkers. 2016;20(7):341-5.

101. Dewey FE, Pan S, Wheeler MT, Quake SR, Ashley EA. DNA sequencing: clinical applications of new DNA sequencing technologies. Circulation. 2012;125(7):931-44.

102. Kurtovic-Kozaric A, Islamagic E, Komic H, Bilalovic N, Eminovic I, Burekovic A, et al. The effects of mutational profiles on phenotypic presentation of myeloproliferative neoplasm subtypes in Bosnia: 18 year follow-up. Bosn J Basic Med Sci. 2020;20(2):236-47.

103. Kang HY, Hwang JY, Kim SH, Goh HG, Kim M, Kim DW. Comparison of allele specific oligonucleotide-polymerase chain reaction and direct sequencing for high throughput screening of ABL kinase domain mutations in chronic myeloid leukemia resistant to imatinib. Haematologica. 2006;91(5):659-62.

104. Genovese G, Kähler AK, Handsaker RE, Lindberg J, Rose SA, Bakhoum SF, et al. Clonal hematopoiesis and bloodcancer risk inferred from blood DNA sequence. N Engl J Med. 2014;371(26):2477-87.
105. Jaiswal S, Fontanillas P, Flannick J, Manning A, Grauman PV, Mar BG, et al. Age-related clonal hematopoiesis associated with adverse outcomes. N Engl J Med. 2014;371(26):2488-98.

106. McKerrell T, Park N, Moreno T, Grove CS, Ponstingl H, Stephens J, et al. Leukemia-associated somatic mutations drive distinct patterns of age-related clonal hemopoiesis. Cell Rep. 2015;10(8):1239-45.

107. Zink F, Stacey SN, Norddahl GL, Frigge ML, Magnusson OT, Jonsdottir I, et al. Clonal hematopoiesis, with and without candidate driver mutations, is common in the elderly. Blood. 2017;130(6):742-52.

108. Logsdon GA, Vollger MR, Eichler EE. Long-read human genome sequencing and its applications. Nat Rev Genet. 2020;21(10):597-614.

109. Duncavage EJ, Schroeder MC, O'Laughlin M, Wilson R, MacMillan S, Bohannon A, et al. Genome Sequencing as an Alternative to Cytogenetic Analysis in Myeloid Cancers. N Engl J Med. 2021;384(10):924-35

110. Vila M, Suljovic E, Bijedic ZMV, Jamakovic M. Epidemiological analysis of leukemias in the period from 1992 to 2010 at the Hematology Clinic, Clinical Center of the University of Sarajevo. In: 1st Congress of Hematologists and Transfusiologists of Bosnia and Herzegovina; 2011 May 19-22; Association of Hematologists and Transfusiologists of Bosnia and Herzegovina; 2002. p. 46.

111. Mehinovic-Cavcic L. Molecular characterization of patients with myeloid neoplasms from the Sarajevo Canton: twenty-year follow-up [dissertation]. Sarajevo: University of Sarajevo, Faculty of Science; 2021.

112. Kurtovic-Kozaric A, Hasic A, Radich JP, Bijedic V, Nefic $\mathrm{H}$, Eminovic I, et al. The reality of cancer treatment in a developing country: the effects of delayed TKI treatment on survival, cytogenetic and molecular responses in chronic myeloid leukemia patients. Br J Hematol. 2016;172(3):420-7.

113. Kurtovic-Kozaric A, Vranic S, Kurtovic S, Hasic A, Kozaric M, Granov N, et al. Lack of Access to Targeted Cancer Treatment Modalities in the Developing World in the Era of Precision Medicine: Real-Life Lessons From Bosnia. J Glob Oncol. 2018;4:1-5.

114. Malhotra H, Radich J, Garcia-Gonzalez P. Meeting the needs of CML patients in resource-poor countries. Hematol Am Soc Hematol Educ Program. 2019;2019(1):43342.

115. Kurtovic-Kozaric A, Islamagic E, Radich JP, Hadzimesic ES, Hasic A, Kurtovic S. The Comparison of Efficacy Between Generic and Branded Imatinib in Achievement of Overall Survival and Cytogenetic Responses in CML Patients in Bosnia and Herzegovina. Blood. 2016;128(22):5451.

116. Islamagic E, Hasic A, Kurtovic S, Hadzimesic ES, Mehinovic L, Kozaric M, et al. The efficacy of generic imatinib as first- and second-line therapy: three year follow-up of 
chronic myeloid leukemia patients. Clin Lymphoma Myeloma Leuk. 2017;17(4):238-40.

117. Islamagic E, Kurtovic S, Kozaric M, Hadzimesic ES, Hasic A, Mehinovic L, et al. The Three Year Follow-up of CML Patients Treated with First-line Generic and First-line Branded Imatinib in Bosnia and Herzegovina. UHOD. 2017;27(1):8-12.

118. Wang J, Shen ZX, Saglio G, Jin J, Huang H, Hu Y, et al. Phase 3 study of nilotinib vs imatinib in Chinese patients with newly diagnosed chronic myeloid leukemia in chronic phase: ENESTchina. Blood. 2015;125(18):2771-8.

119. Hochhaus A, Rosti G, Cross NC, Steegmann JL, le Coutre P, Ossenkoppele G, et al. Frontline nilotinib in patients with chronic myeloid leukemia in chronic phase: results from the European ENEST1st study. Leukemia. 2016;30(1):57-64.

120. Cortes JE, Kim DW, Kantarjian HM, Brümmendorf TH, Dyagil I, Griskevicius L, et al. Bosutinib versus imatinib in newly diagnosed chronic-phase chronic myeloid leukemia: results from the BELA trial. J Clin Oncol. 2012;30(28):3486-92.

121. Radich JP, Kopecky KJ, Appelbaum FR, Kamel-Reid S, Stock W, Malnassy G, et al. A randomized trial of dasatinib $100 \mathrm{mg}$ versus imatinib $400 \mathrm{mg}$ in newly diagnosed chronic-phase chronic myeloid leukemia. Blood. 2012;120(19):3898-905.

122. Islamagic E, Hasic A, Kurtovic S, Suljevic D, Kozaric M, Eminovic I, et al. Clinical Outcomes of CML Patients After Delayed Start of Nilotinib Treatment. UHOD. 2021;31(1):19-27.

123. Westerweel PE, Te Boekhorst PAW, Levin MD, Cornelissen JJ. New Approaches and Treatment Combinations for the Management of Chronic Myeloid Leukemia. Front Oncol. 2019;9:665.

124. Hughes TP, Mauro MJ, Cortes JE, Minami H, Rea D, DeAngelo DJ, et al. Asciminib in Chronic Myeloid Leukemia after ABL Kinase Inhibitor Failure. N Engl J Med. 2019;381(24):2315-26. 